ARTICLE

\title{
A guanidine-degrading enzyme controls genomic stability of ethylene-producing cyanobacteria
}

\author{
Bo Wang (1) ${ }^{1,2 \bowtie}$, Yao Xu ${ }^{3}$, Xin Wang (i] ${ }^{4,6}$, Joshua S. Yuan (1] ${ }^{4}$, Carl H. Johnson ${ }^{3}$, Jamey D. Young (i) ${ }^{2,5} \&$ \\ Jianping $Y u(D){ }^{1 凶}$
}

Recent studies have revealed the prevalence and biological significance of guanidine metabolism in nature. However, the metabolic pathways used by microbes to degrade guanidine or mitigate its toxicity have not been widely studied. Here, via comparative proteomics and subsequent experimental validation, we demonstrate that SII1077, previously annotated as an agmatinase enzyme in the model cyanobacterium Synechocystis sp. PCC 6803, is more likely a guanidinase as it can break down guanidine rather than agmatine into urea and ammonium. The model cyanobacterium Synechococcus elongatus PCC 7942 strain engineered to express the bacterial ethylene-forming enzyme (EFE) exhibits unstable ethylene production due to toxicity and genomic instability induced by accumulation of the EFE-byproduct guanidine. Coexpression of EFE and Sll1077 significantly enhances genomic stability and enables the resulting strain to achieve sustained high-level ethylene production. These findings expand our knowledge of natural guanidine degradation pathways and demonstrate their biotechnological application to support ethylene bioproduction.

\footnotetext{
${ }^{1}$ Biosciences Center, National Renewable Energy Laboratory, Golden, CO, USA. ${ }^{2}$ Department of Chemical and Biomolecular Engineering, Vanderbilt University, Nashville, TN, USA. ${ }^{3}$ Department of Biological Sciences, Vanderbilt University, Nashville, TN, USA. ${ }^{4}$ Synthetic and Systems Biology Innovation Hub, Department of Plant Pathology and Microbiology, Texas A\&M University, College Station, TX, USA. ${ }^{5}$ Department of Molecular Physiology and Biophysics, Vanderbilt University, Nashville, TN, USA. ${ }^{6}$ Present address: Department of Microbiology, Miami University, Oxford, OH, USA.

凶email: bo.wang.vu@gmail.com; Jianping.Yu@nrel.gov
} 
$\mathrm{D}$ espite the practical applications of guanidine as a protein denaturant (when applied at high concentrations) $)^{1}$ and as an ingredient in slow-release fertilizers ${ }^{2}$, little is known about the fate of guanidine in biological systems. Guanidine has been detected in human urine at concentrations of $7-13 \mathrm{mg} \mathrm{L}^{-1}$ $(0.12-0.22 \mathrm{mM})^{3}$, but its biosynthetic pathway remains elusive ${ }^{4}$. A recent study also revealed that a variety of microorganisms, including $E$. coli, produce guanidine through unknown mechanisms under nutrient-poor growth conditions, suggesting that guanidine metabolism is biologically significant and is prevalent in natural environments 5 .

While nonenzymatic decomposition of guanidine under physiological conditions is very slow ${ }^{6}$, soil microbes are able to degrade guanidine using heretofore unknown metabolic pathways ${ }^{7}$. Recently, it was reported that a wide range of microorganisms possesses a class of guanidine riboswitches that control the expression of downstream genes, a majority of which encode proteins involved in nitrogen metabolism, nitrate/sulfate/ bicarbonate transport, and guanidine export ${ }^{5,8-12}$. A previously annotated urea carboxylase was reported to carboxylate guanidine to form carboxyguanidine $e^{5}$, which is degraded by a carboxyguanidine deiminase followed by further degradation by allophanate hydrolase ${ }^{13}$. Another class of enzymes regulated by guanidine riboswitches are annotated as agmatinases in the arginase superfamily $y^{5,9,14,15}$, which catalyze the breaking of C-N bonds in the guanidyl moiety of agmatine, releasing urea ${ }^{16}$. There is no current explanation for why these enzymes evolved regulation in response to free guanidine.

To date, the only known enzyme that produces guanidine is the ethylene-forming enzyme (EFE) that catalyzes the formation of ethylene and guanidine simultaneously from a-ketoglutarate (AKG) and arginine ${ }^{17}$. Due to biotechnological interests in developing an alternative pathway for renewable production of ethylene, which is the most highly produced organic compound in the petro-chemical industry, the efe gene from Pseudomonas syringae (a plant pathogen) has been introduced into a variety of microbial species ${ }^{17}$. Some hosts, e.g., Pseudomonas putida KT2440 and the cyanobacterium Synechocystis sp. PCC 6803 (hereafter Synechocystis 6803), have been able to accommodate stable, high-level expression of EFE and thereby sustain enhanced production of ethylene ${ }^{17-22}$. Other species, such as cyanobacterium Synechococcus elongatus PCC 7942 (hereafter Synechococcus 7942) and Synechococcus elongatus PCC 11801 (hereafter Synechococcus 11801), however, have not been able to tolerate the high-level expression of EFE, and the recombinant strains suffered severe growth inhibition ${ }^{23-25}$ and genome instability. More specifically, spontaneous mutations were found at various sites within the EFE open reading frame in the recombinant Synechococcus 7942 strain, which eventually abolished the expression of functional EFE and rescued the growth inhibition ${ }^{23,24}$.

In this study, we report a guanidine-degrading enzyme discovered through comparative analysis of multiple cyanobacterial species. We show that guanidine possesses significant toxicity to cyanobacterial cells and destabilizes their genome in response to recombinant EFE expression. Synechocystis 6803 is able to degrade and utilize guanidine as a nitrogen source through the activity of an enzyme encoded by the gene sll1077, which was previously annotated as an agmatinase in the arginase superfamily. We posit that Sll1077 is more likely a guanidinase because it degrades guanidine rather than agmatine into urea and ammonium. This result is consistent with the finding that there is a conserved sequence motif of the guanidine riboswitch upstream of the sll1077 ORF in the genome of the wild-type Synechocystis 6803 strain. Synechococcus 7942 lacks a homologous enzyme in its genome and is unable to mitigate guanidine toxicity. We find that heterologous expression of Sll1077 in a recombinant
Synechococcus 7942 strain confers the ability to degrade guanidine into nontoxic urea. Co-expression of Sll1077 and EFE in Synechococcus 7942 stabilizes the genome of the resultant strain and leads to sustained production of ethylene from light and $\mathrm{CO}_{2}$.

\section{Results}

Varied guanidine-degradation abilities of cyanobacterial species. Given that the impacts of guanidine on microorganisms are unclear, we studied guanidine degradability and toxicity in two model cyanobacterial species: Synechocystis 6803 and Synechococcus 7942. In our preliminary experiments with Synechocystis 6803 , when nitrate was gradually replaced with guanidine in the culture medium, the guanidine concentrations declined over a period of four days in all cases under photoautotrophic cultivation conditions (Supplementary Fig. 1). In order to rule out the possibility of photochemical degradation, Synechocystis 6803 cells were resuspended in the nitrate-deprived mBG11 medium with or without $5 \mathrm{mM}$ guanidine (detailed in "Methods"). In parallel, Synechococcus 7942 and heat-killed Synechocystis 6803 cells were also resuspended in the nitrate-deprived culture medium supplemented with $5 \mathrm{mM}$ guanidine. We found that Synechocystis 6803 cells grown in nitrate-deprived medium exhibited the expected chlorosis phenotype, a process involving degradation of photosynthesis-related pigments to recycle nitrogen for biomass production $^{26}$. As a result, the cultures were still able to double the amount of biomass. On the other hand, cells grown in the guanidine-supplemented medium were able to maintain their green pigmentation and reached a higher cell density after 6 days of photoautotrophic cultivation (Fig. 1a, b). Noticeably, the Synechocystis 6803 cells exposed to exogenous guanidine had a slower growth rate than those not exposed to guanidine during the first day, probably due to the toxicity of guanidine (Fig. 1a, b). By contrast, the cultures inoculated with heat-killed Synechocystis 6803 or live Synechococcus 7942 cells showed a continuous decline of biomass over the period of 6 days (Fig. 1a, b). While the guanidine content in the culture with Synechococcus 7942 or heatkilled Synechocystis cells did not decline, the continuous increase of biomass in the culture of live Synechocystis 6803 cells coincided with a steady decrease of the guanidine concentration in the culture medium (Fig. 1c). To this end, we hypothesized that a guanidine-degrading metabolic pathway may exist in Synechocystis 6803 but not in Synechococcus 7942 .

Sl11077 confers guanidine degradation in Synechocystis 6803. A comparative proteomic study of the wild-type Synechocystis 6803 and the guanidine-producing (efe-expressing) strain, JU54727, showed that the expression of S111077, a putative agmatinase, increased by 20 -fold in strain JU547 compared to that in the wildtype Synechocystis 6803 (Supplementary Data 1). Agmatinase cleaves the $\mathrm{C}-\mathrm{N}$ bond within the guanidyl moiety of agmatine, which releases putrescine and urea $^{28}$. Interestingly, the expression of sll1077 is predicted to be under the control of a guanidine riboswitch based on analysis of the RNA sequence upstream of its ORF (Fig. 2a, b) ${ }^{5}$. We hypothesized that Sll1077 might be involved in the metabolism of guanidine in Synechocystis 6803 (Fig. 2c). Knockout of sll1077 in Synechocystis 6803, leading to strain PB805W ( $\Delta$ sll1077), did not have any apparent physiological effects on the cells under normal growth conditions (Supplementary Fig. 2), or under nitrate-deprived conditions (Fig. 2d, e). Nevertheless, under nitrate-deprived guanidine-supplemented culture conditions, the cell growth of $\Delta$ sll1077 was severely inhibited compared to the wild-type Synechocystis 6803 and the degradation of the light-harvesting components, i.e., phycobilisomes (absorbance at $630 \mathrm{~nm}$ ) and chlorophyll $a$ (absorbance at $680 \mathrm{~nm})$, in $\Delta$ sll1077 was remarkably retarded compared to the 
a

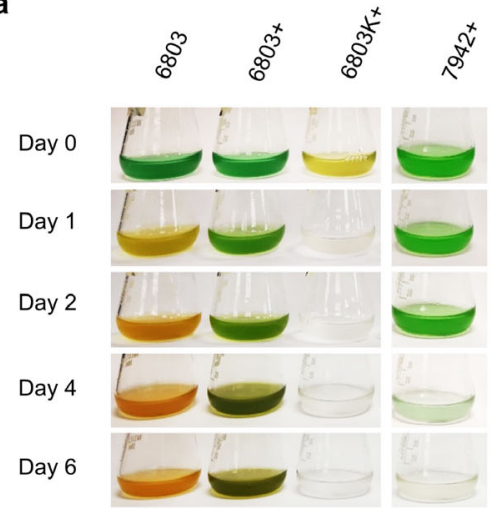

b

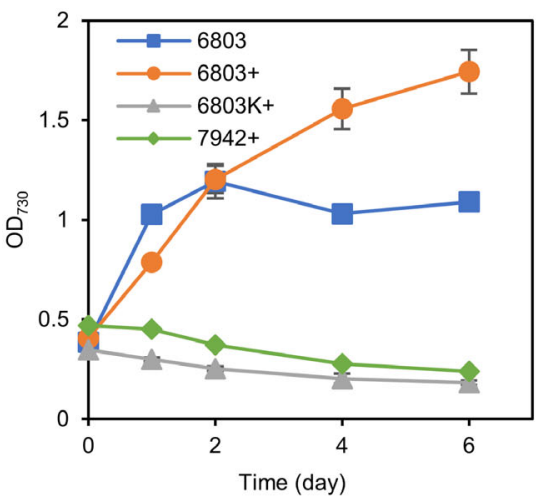

C

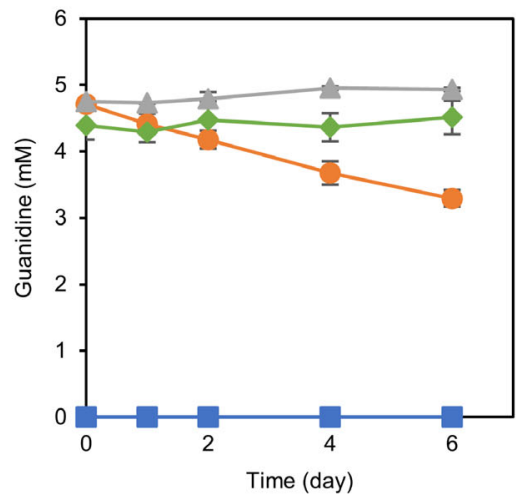

Fig. 1 Varied capabilities in degrading guanidine between two model cyanobacterial species. a Phenotypes of Synechocystis 6803 and Synechococcus 7942 grown in nitrate-deprived medium with or without guanidine. 6803, Synechocystis 6803 strain grown in the nitrate-deprived medium; $6803+$, Synechocystis 6803 strain grown in nitrate-deprived medium supplemented with $5 \mathrm{mM}$ guanidine. $6803 \mathrm{~K}+$, Synechocystis 6803 cells initially killed by heating at $95^{\circ} \mathrm{C}$ for $10 \mathrm{~min}$ and then resuspended in the nitrate-deprived medium supplemented with 5 mM guanidine. $7942+$, Synechococcus 7942 strain grown in nitrate-deprived medium supplemented with $5 \mathrm{mM}$ guanidine. $\mathbf{b}$ Time courses of cell mass accumulation as monitored by absorbance at $730 \mathrm{~nm}$ $\left(\mathrm{OD}_{730}\right)$. c Time courses of guanidine concentrations in the culture supernatants. Data represent means and standard deviations from three biological replicates. Source data underlying panels $(\mathbf{b}, \mathbf{c})$ are provided as a Source Data file.

wild-type Synechocystis 6803 or $\Delta$ sll1077 cultivated in the medium without guanidine (Fig. $2 \mathrm{~d}-\mathrm{f}$ ). Further analysis revealed that the guanidine-degradation capability was abolished in the Synechocystis $\Delta$ sll1077 strain (Fig. $2 \mathrm{~g}$ ), a phenotype similar to that of wild-type Synechococcus 7942 (Fig. 1a). In addition, during the first day, the biomass of strain $\Delta$ sll1077 incubated with guanidine increased to a much less extent relative to other parallel cases; in the next few days, the biomass of strain $\Delta$ sll1077 incubated with guanidine underwent an autolysis process and the lightharvesting complex gradually deteriorated (Fig. 2d-f).

Overexpression of sll1077 in Synechocystis 6803 was achieved through optimizing the ribosome-binding site (RBS) at the 5'region as well as tailoring the 3'-region of the expression cassette (Fig. 3a). Among the six tested RBSs, RBSv309 in strain PB809W rendered the strongest expression level (Fig. $3 \mathrm{~b}$ and Supplementary Fig. 3). While removal of the XhoI restriction site between the sll1077 and the $6 \times \mathrm{xHis}$ tag sequence at the 3 '-region in strain PB812W did not have any apparent effect on the sll1077 expression level, adding the rrnBT1T2 terminator (from E. coli) to the 3'-region significantly improved the expression of sll1077 in PB816W (Fig. 3a, b). Strain PB816W was able to degrade guanidine at a rate $\sim 80 \%$ faster than the wild-type Synechocystis 6803 , which led to a faster cell growth rate in nitrate-deprived medium supplemented with guanidine (Fig. 3c, d). Interestingly, although removal of the $6 \mathrm{xHis}$ tag sequence from the 3 ' end of sll1077 did not affect the protein expression level (Fig. $3 \mathrm{~b}$ and Supplementary Fig. 3), it increased the guanidine-degradation rate by about two times and substantially increased the cell growth rate of $\mathrm{PB} 817 \mathrm{~W}$ (Fig. 3c, d), suggesting that the C-terminus $6 \mathrm{xHis}$ tag negatively impairs the guanidinedegrading enzyme activity of Sll1077.

In order to verify that guanidine is degraded by S1l1077 to form urea, according to the enzymatic mechanism of the agmatinase/ arginase superfamily ${ }^{28}$, Sll1077-His was purified from the crude cell lysate of Synechocystis strain PB816W (Figs. 3b and 4a and Supplementary Fig. 4; note that S1l1077 in strain PB817W does not have a His tag for purifying the protein from the cell lysate). Purified Sll1077-His showed an apparent molecular weight of $\sim 45 \mathrm{kDa}$ which is consistent with the predicted molecular weight of $43.8 \mathrm{kDa}$ (Fig. 4a). Incubation of purified Sll1077-His with guanidine at $30{ }^{\circ} \mathrm{C}$ resulted in hydrolysis of guanidine and release of urea and ammonium (Fig. $4 \mathrm{~b}-\mathrm{e}$ ). We further calculated the enzyme kinetic parameters, $V_{\max }=0.055 \pm 0.014 \mathrm{U} \mathrm{mg}^{-1}, K_{\mathrm{M}}=$ $5.3 \pm 1.2 \mathrm{mM}, \quad k_{\mathrm{cat}}=0.040 \pm 0.010 \mathrm{~s}^{-1}$, and $k_{\mathrm{cat}} / K_{\mathrm{M}}=0.0076 \pm$ $0.0006 \mathrm{~s}^{-1} \mathrm{mM}^{-1}$ (Fig. 4f, g). Considering that the His tag inhibits the enzyme activity of Sll1077 by about 2.5 -fold under the examined experimental condition (Fig. $3 \mathrm{c}$ and Supplementary Fig. 5), the $k_{\text {cat }}$ for Sll1077 without a His tag is expected to be higher than that shown in Fig. 4g. It is noteworthy that no cofactors, such as ATP or $\mathrm{NAD}(\mathrm{P}) \mathrm{H}$, are required to drive the guanidine hydrolysis enzymatic activity of Sll1077, and the presence of ATP has no significant effect on the enzymatic activity of Sll1077 (Supplementary Fig. 6). Therefore, the hydrolytic nature of S1l1077 is more energy-efficient compared to the previously reported guanidine carboxylation pathway ${ }^{5,13}$ (Fig. 4h).

Expression of sll1077 improves cell tolerance to guanidine. In order to examine if expressing a recombinant enzyme, Sll1077 from Synechocystis 6803, could endow the guanidine-degradation capability in a host strain that does not naturally degrade guanidine, we expressed sll1077 in Synechococcus 7942, resulting in strain GD7942 (+sll1077). While the cell growth of Synechococcus 7942 was already inhibited by guanidine at concentrations as low as $0.3 \mathrm{mM}$ and was severely inhibited by $1 \mathrm{mM}$ guanidine under photoautotrophic conditions (Fig. 5a), the sll1077-expressing strain GD7942 gained significant tolerance to exogenous guanidine. Particularly, the cell growth of strain GD7942 was not noticeably repressed by as much as $1 \mathrm{mM}$ guanidine present in the culture medium and was only slightly inhibited by $2 \mathrm{mM}$ guanidine (Fig. 5a). We further examined the fate of the exogenous guanidine in the culture medium containing $1 \mathrm{mM}$ guanidine. As expected, while no guanidine degradation occurred in the culture of wild-type Synechococcus 7942, the guanidine added into the culture medium of the GD7942 strain was completely degraded over 4 days of photoautotrophic cultivation (Fig. 5b). Since the wild-type Synechococcus 7942 does not have any urea biosynthesis or degradation pathways ${ }^{29}$, it was expected that urea would be accumulated in the GD7942 culture. Indeed, along with the degradation of guanidine, urea gradually accumulated in the culture supernatants to concentrations of about $1 \mathrm{mM}$ by end of day 4 (Fig. 5b), which is consistent with the pathway annotation ${ }^{29}$ and enzymatic reaction stoichiometry (Fig. 4h). We further found that supplementing $5 \mathrm{mM}$ urea into the culture medium of 
a

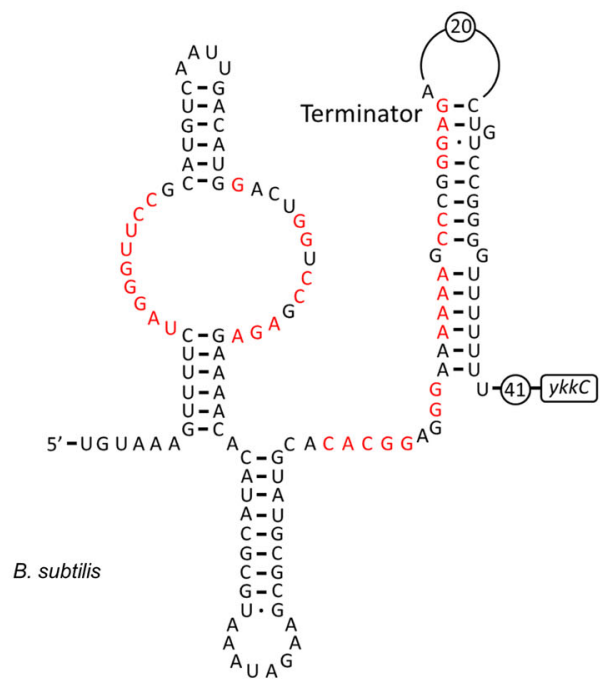

b

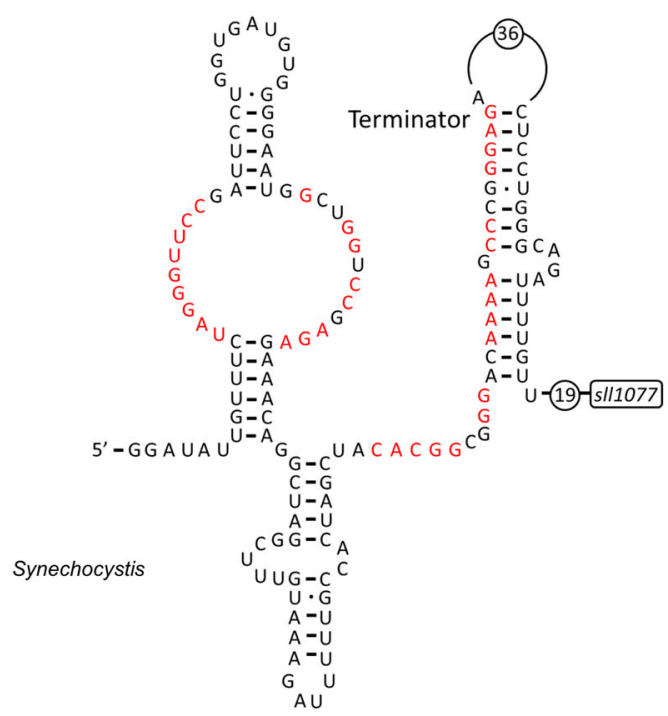

c

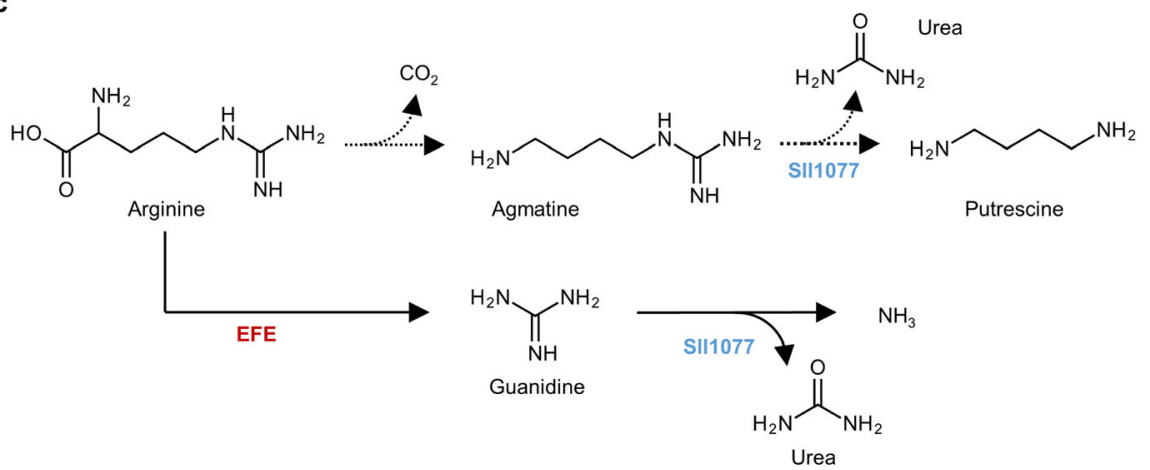

e

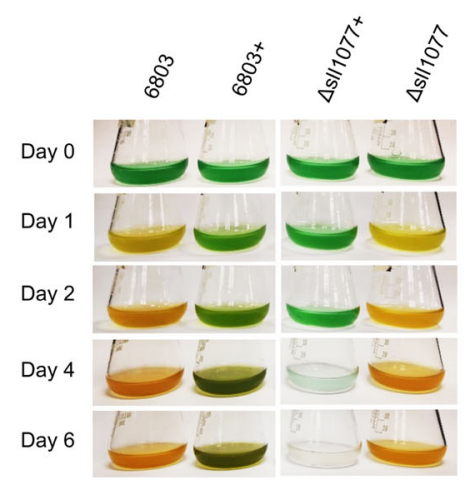

f

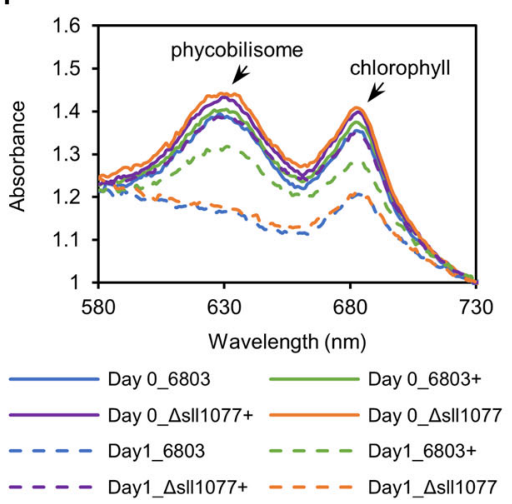

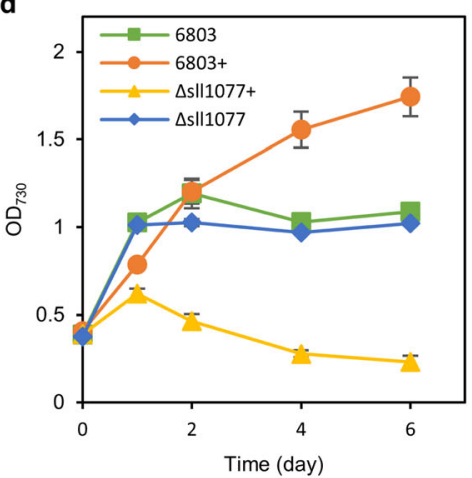

g

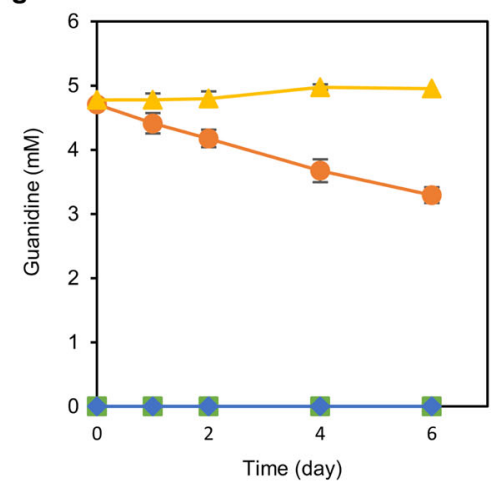

Fig. 2 Gene sll1077 is responsible for guanidine degradation in Synechocystis 6803. a The secondary RNA structure of the guanidine riboswitch upstream of the guanidine exporter encoded by the $y k k C$ gene in Bacillus subtilis. Nucleotides in red are $>97 \%$ conserved in type I guanidine riboswitch 5 . b The secondary RNA structure of predicted guanidine riboswitch upstream of the s/11077 gene in Synechocystis 6803 . The consensus guanidine riboswitch nucleotides are depicted in red. c The proposed metabolic role of SII1077 in degrading guanidine as depicted by solid arrows. Sll1077 was previously annotated as an agmatinase in one arginine degradation pathway as depicted by the dotted arrows ${ }^{15}$. $\mathbf{d}$ Time courses of cell densities of Synechocystis 6803 and the $\Delta$ s/11077 strain (PB805W) grown in nitrate-deprived medium with or without guanidine supplementation. In total, $5 \mathrm{mM}$ guanidine was added into the nitrate-deprived medium as indicated by " + " following the strain names. e Phenotypes of Synechocystis 6803 and the $\Delta$ s/l1077 strain (PB805W). f Absorbance spectra of cultures at day 0 and day 1 as shown in $\mathbf{d}$. Absorbance was normalized to absorbance at $730 \mathrm{~nm}$. $\mathbf{g}$ Time courses of guanidine concentrations in the culture supernatants. Data represent means and standard deviations from three biological replicates. Source data underlying panels $(\mathbf{d}, \mathbf{g})$ are provided as a Source Data file.

Synechococcus 7942 did not show any apparent impact on the cell growth under either nitrate-deprived or nitrate-containing culture conditions (Supplementary Fig. 7), suggesting that Synechococcus 7942 is highly tolerant to urea.
Sll1077 prefers guanidine rather than agmatine as the substrate. To examine the substrate preference of Sll1077 toward guanidine and agmatine, the crude cell extract of Synechococcus 7942 and GD7942 was incubated with $5 \mathrm{mM}$ of either guanidine 
a

PB806W: AATTGTGAGCGGATAACAATTTCACACAAGGAGGATATACAT PB807W: AATTGTGAGCGGATAACAATTTCACACAAGGAGGAAACAT PB808W: AATTGTGAGCGGATAACAATTTCACACAAGGAGGAACAGC PB809W: AATTGTGAGCGGATAACAATTTCACACAAGGAGAAACAGC PB810W: AATTGTGAGCGGATAACAATTTCACACAAGAAGGAGAAACAGC PB811W: AATTGTGAGCGGATAACAATTTCACACAAGAAGGAGAAACATAGC PB812W: AATTGTGAGCGGATAACAATTTCACACAAGGAGAAACAGC PB816W: AATTGTGAGCGGATAACAATTTCACACAAGGAGAAACAGC PB817W: AATTGTGAGCGGATAACAATTTCACACAAGGAGAAACAGC

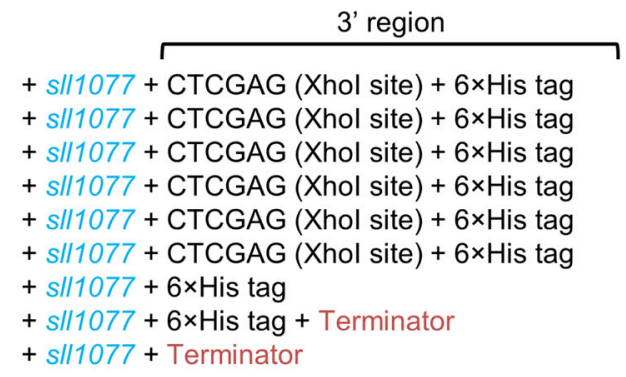

b

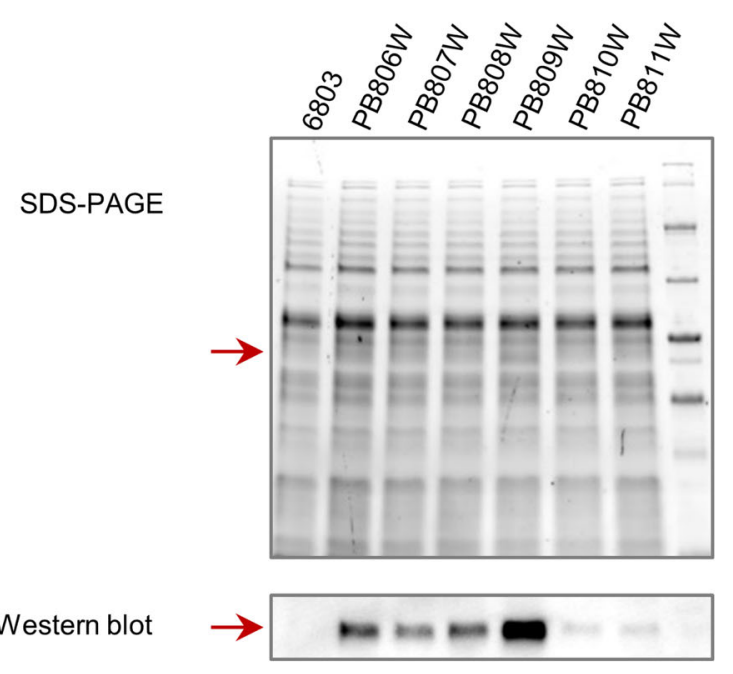
$\underline{\mathrm{kDa}}$
250
150
100
70
50
40
30
20
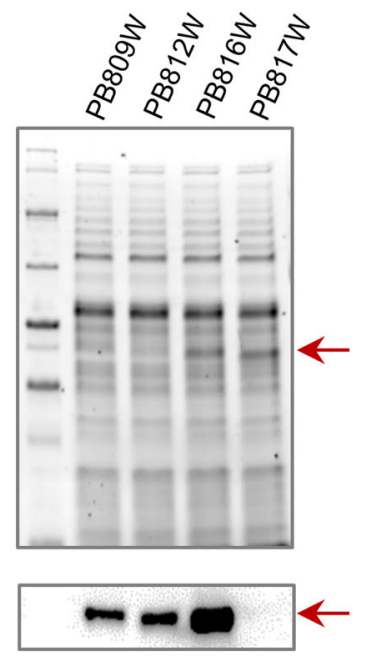

d

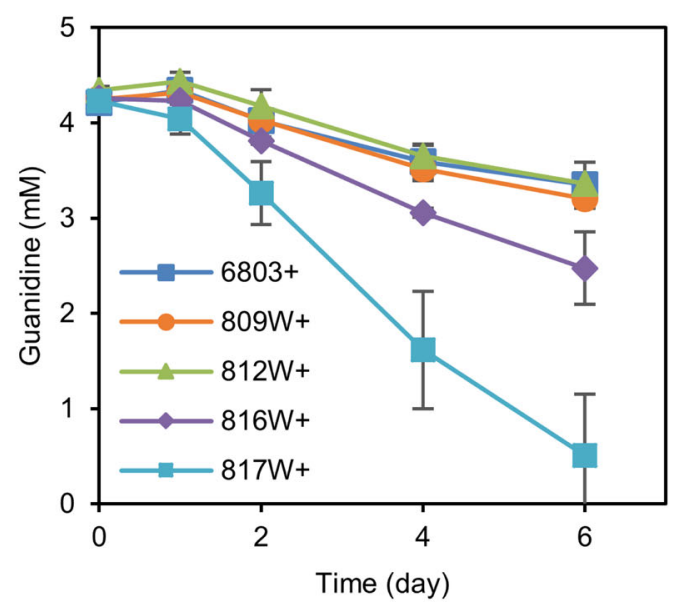

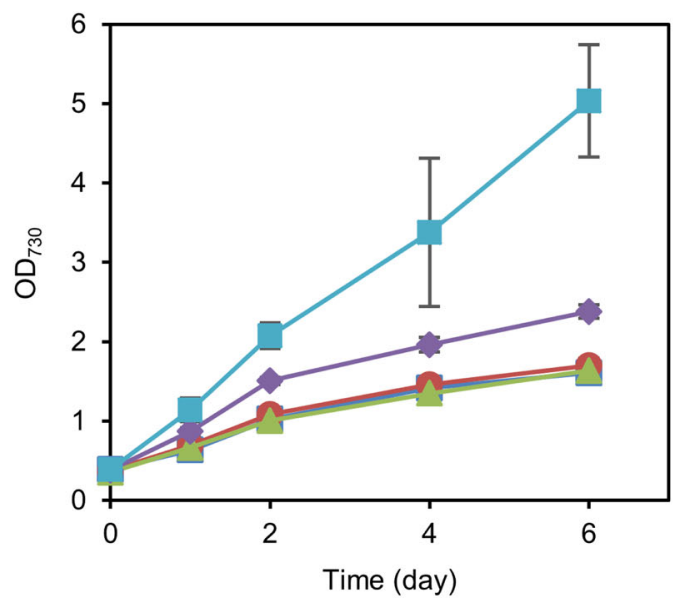

Fig. 3 Overexpression of SII1077 accelerates guanidine degradation and promotes biomass growth in Synechocystis 6803. a Strategies for enhancing the overexpression of gene s/17077 in Synechocystis 6803. Gene s/l1077 was overexpressed driven by the tac promoter, with its RBS (purple nucleotides, including the entire $5^{\prime}$-untranslated sequence upstream of the start codon of gene sll1077) at the $5^{\prime}$-region and the His tag and terminator at the $3^{\prime}$-region optimized. b SDS-PAGE and western blotting (His tag) showing the improved expression of SII1077 in Synechocystis. Representative data from two independent experiments. c Guanidine-degradation profiles of Synechocystis 6803 and sll1077-overexpressing strains. d Cell growth curves for Synechocystis 6803 and s/1077-overexpressing strains, indicated by readings of $\mathrm{OD}_{730}$ of cell cultures. Data represent means and standard deviations from three biological replicates. Source data underlying panels $(\mathbf{c}, \mathbf{d})$ are provided as a Source Data file.

or agmatine at $30^{\circ} \mathrm{C}$. Surprisingly, we found that the crude cell extract of GD7942 was able to degrade guanidine but not agmatine. The concentration of guanidine incubated with the GD7942 cell lysate decreased by about $2 \mathrm{mM}$, and concomitantly $\sim 2 \mathrm{mM}$ urea was produced in the reaction mix over the examined $12 \mathrm{~h}$ time period (Fig. 5c, d). In contrast, neither guanidine was consumed nor urea was produced in any other examined cases (Fig. 5c, d). We, therefore, propose denominating Sll1077 as a guanidinase instead of an agmatinase.

Co-expression of S111077 and EFE enhances genomic stability. Given that the EFE reaction produces not only ethylene but also 
a

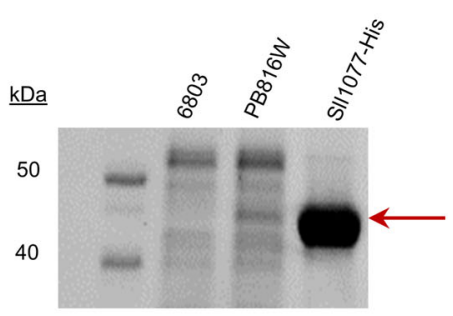

c

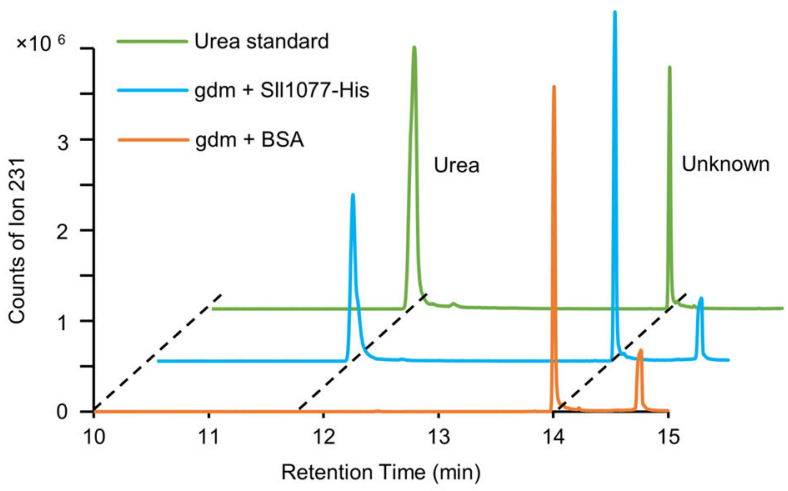

e

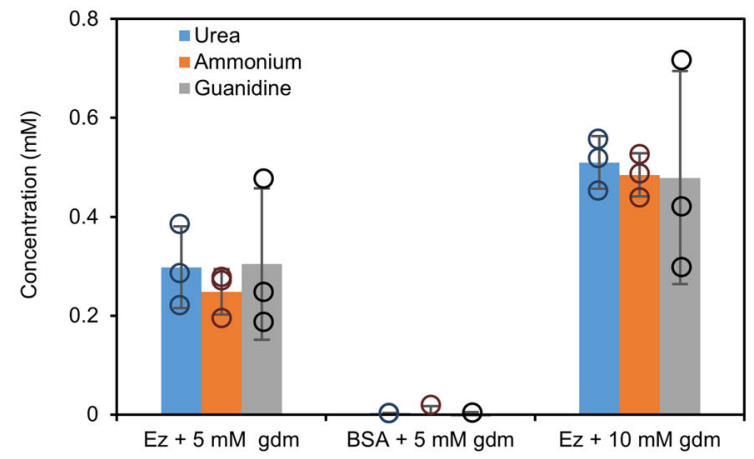

b

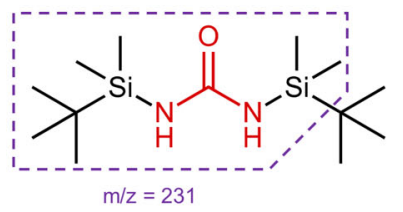

d

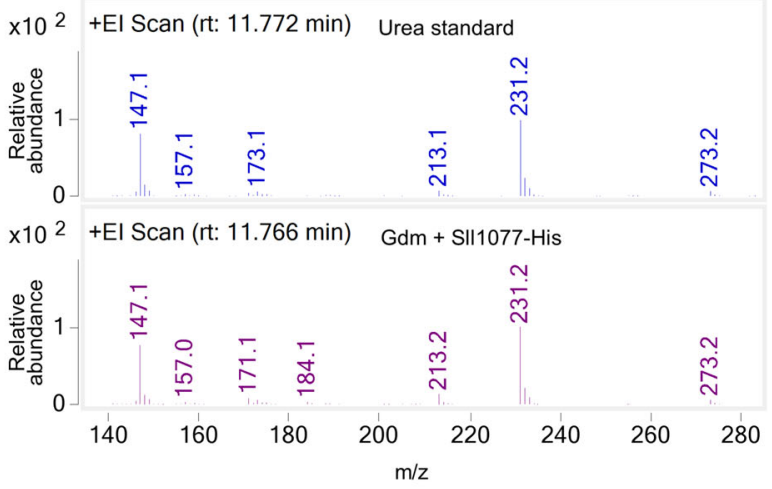

$\mathbf{f}$

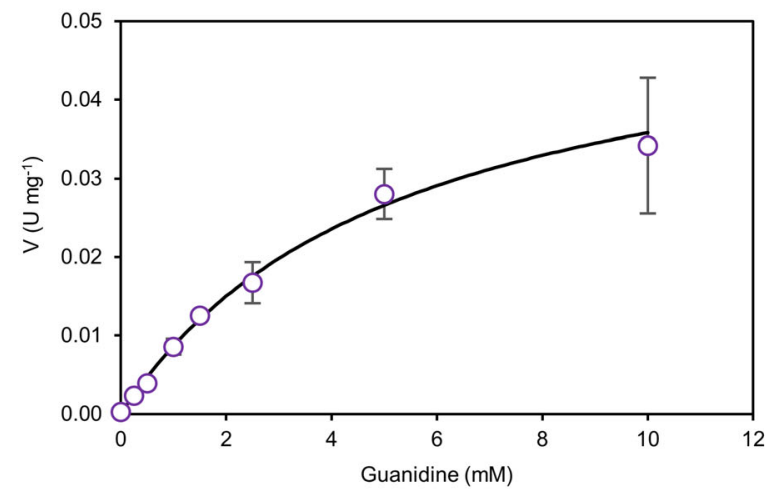

g

\begin{tabular}{cccc}
\hline $\mathrm{V}_{\max }\left(\mathrm{U} \mathrm{mg}^{-1}\right)$ & $\mathrm{K}_{\mathrm{M}}(\mathrm{mM})$ & $\mathrm{K}_{\text {cat }}\left(\mathrm{s}^{-1}\right)$ & $\mathrm{K}_{\mathrm{cat}} / \mathrm{K}_{\mathrm{M}}\left(\mathrm{s}^{-1} \mathrm{mM}^{-1}\right)$ \\
\hline $0.055 \pm 0.014$ & $5.3 \pm 1.2$ & $0.040 \pm 0.010$ & $0.0076 \pm 0.0006$ \\
\hline
\end{tabular}

h

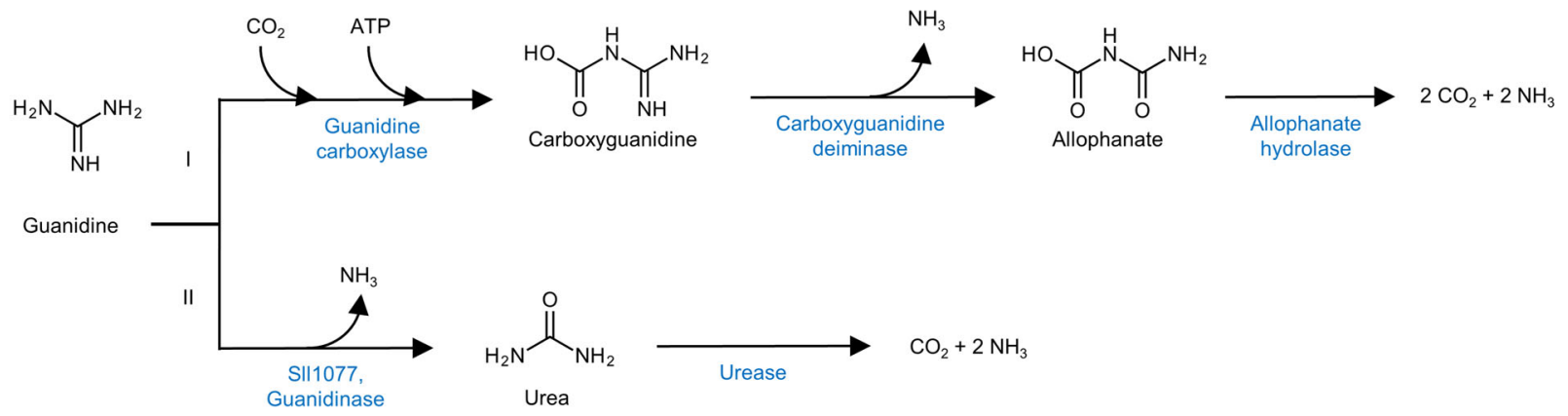

toxic guanidine, which might be responsible for the genomic instability observed upon expression of EFE alone in Synechococcus $7942^{23,24}$, we examined if co-expressing Sll1077 and EFE in the Synechococcus 7942 host strain would render a stable genome and thereby sustained production of ethylene. We found that following the genetic transformation of Synechococcus 7942 and colony restreaking on BG11 agar plates, the recombinant efe- expressing strain, EFE7942, grew considerably slower than wildtype and the initially formed colonies appeared yellow-greenish; subsequently, large and dark-green colonies grew up on the background of the smaller colonies (Fig. 6a). Cultivation of these large and small colonies in the liquid culture revealed that cells from the small colonies, but not from the large ones, retained photosynthetic ethylene productivity. Subsequent colony PCR 
Fig. 4 Confirmation of the guanidine-degrading enzyme activity of SIl1077 through an in vitro enzyme activity assay. a SDS-PAGE showing the cell extract from Synechocystis 6803, PB816W, and purified SIl1077-His. Representative data from two independent experiments. b TBDMS derivative of urea. Red font indicates the urea backbone. The boxed portion indicates the main ion detected by GC-MS. c lon counts of ion 231 for TBDMS derivative of urea standard or the TBDMS derivative of the product of reaction mix incubating $5 \mathrm{mM}$ guanidine with either SII1077-His ("gdm + Sll1077-His") or bovine serum albumin ("gdm + BSA") for 3 h. d Mass spectra of the peaks at $11.77 \mathrm{~min}$ in c. e Consumed guanidine and produced urea and ammonium from the reaction mix containing guanidine. "Ez" stands for SIl1077-His enzyme. The reaction was allowed to proceed for $3 \mathrm{~h}$. $\mathbf{f}$ Plot of the velocities of Sll1077-His versus the concentration of guanidine. $U, \mu \mathrm{mol} \mathrm{min}^{-1}$. $\mathbf{g}$ Calculated enzymatic properties of Sll1077-His. Since the His tag inhibits the enzyme activity of SII1077 by about 2.5-fold under the examined experimental condition (Fig. $3 \mathrm{c}$ and Supplementary Fig. S9), the $k_{\text {cat }}$ for Sll1077 without a His tag is expected to be higher than the value shown herein. $\mathbf{h}$ Guanidine-degradation pathways identified to date. Pathway I was reported previously, and pathway II is demonstrated in the current study. Data in $(\mathbf{c}, \mathbf{d})$ are representative results from three independent biological replicates, and data in (e-g) represent means and standard deviations from three independent biological replicates. Source data underlying panels $\mathbf{e}-\mathbf{g}$ are provided as a Source Data file.

a

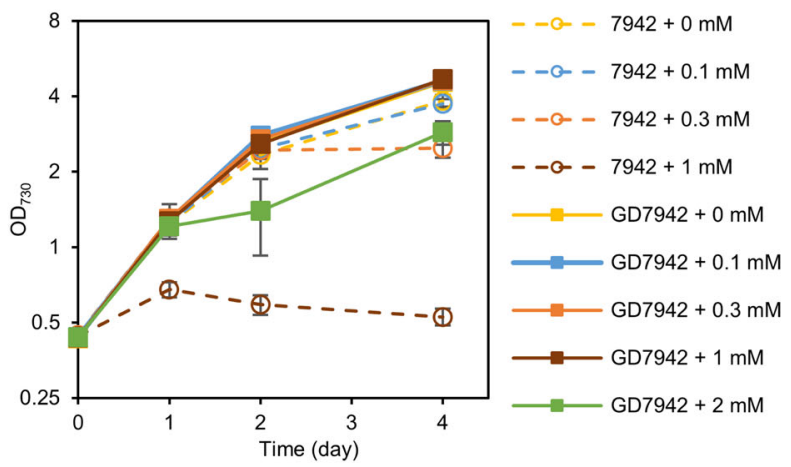

c

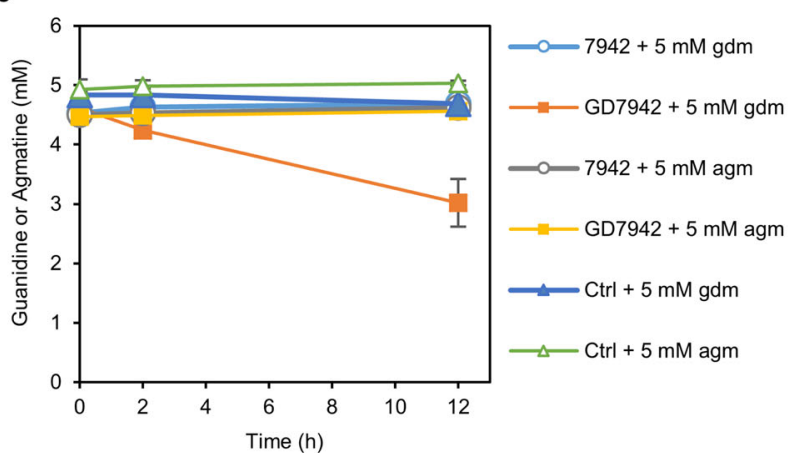

b

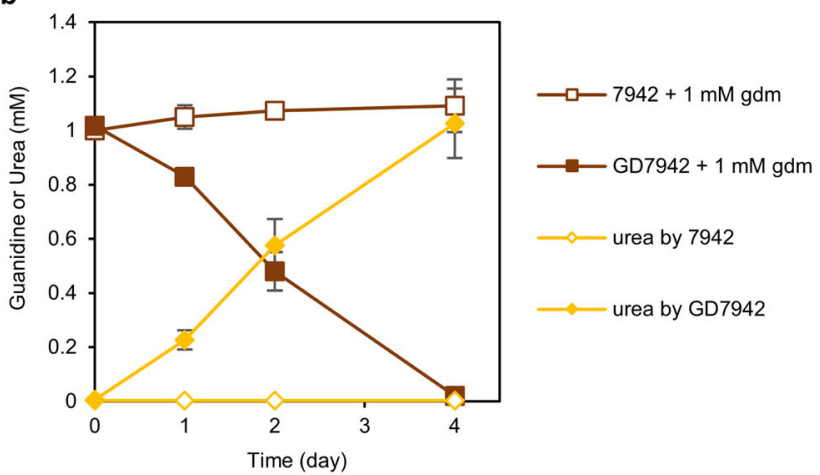

d

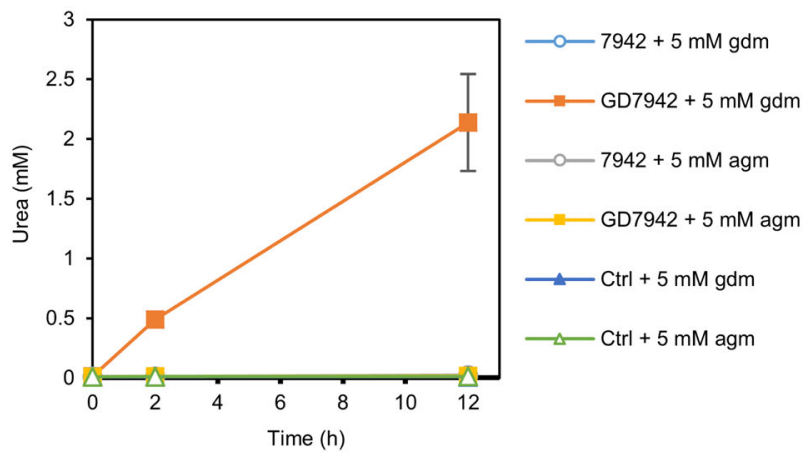

Fig. 5 Expression of sll1077 improves the tolerance of Synechococcus $\mathbf{7 9 4 2}$ to guanidine. a Cell growth curves for the Synechococcus 7942 and GD7942 ( + sll1077) grown with various concentrations of exogenous guanidine in the mBG11 medium supplemented with 50 mM bicarbonate. b Time courses of guanidine and urea concentrations in the culture supernatants of Synechococcus 7942 and GD7942 grown with 1 mM guanidine. c Concentrations of guanidine or agmatine in the enzymatic reaction mix along the time course. Either $5 \mathrm{mM}$ guanidine (gdm) or agmatine (agm) was incubated with cell extract of Synechococcus 7942 or GD7942. Control (Ctrl) included all the components but the cell extract. d Production of urea by the cell extract of Synechococcus 7942 or GD7942 incubated with 5 mM guanidine ( $\mathrm{gdm}$ ) or agmatine (agm). All measured urea concentrations were close to zero except for 'GD7942 + 5 mM gdm'. Data represent means and standard deviations from three biological replicates. Source data are provided as a Source Data file.

and DNA sequencing results confirmed that cells from the small colonies retained the correct EFE expression cassette on their genomes, whereas the large colonies consisted of cells with mutations around the EFE expression cassette which abolished expression of EFE (Supplementary Fig. 8). It is noteworthy that restreaking single small colonies onto fresh mBG11-agar plates supplemented with spectinomycin repeatedly resulted in a mixture of large and small colonies after 1-2 weeks of incubation at $30^{\circ} \mathrm{C}$, indicating a constant selective pressure caused by the expression of EFE. In contrast, co-expression of Sll1077 with EFE in Synechococcus strain GD-EFE7942 resulted in uniform colony sizes on agar plates at $30{ }^{\circ} \mathrm{C}$ (Fig. 6a), and colony PCR and DNA sequencing confirmed that these cells were able to maintain the intact EFE expression cassette on their genome (Supplementary Fig. 8), indicating relief of the selective pressure caused by the expression of EFE. Because EFE exhibits the highest enzyme activity in the temperature range of $20-25^{\circ} \mathrm{C}$ and becomes unstable at temperature above $30^{\circ} \mathrm{C}^{30,31}$, we decided to routinely maintain strain EFE7942 at $35^{\circ} \mathrm{C}$ to suppress the EFE activity and thereby prevent spontaneous mutations from occurring.

The wild-type Synechococcus 7942 strain and the efe-expressing strains EFE7942 and GD-EFE7942 were then compared in regard to their cell growth rates and ethylene productivities in liquid cultures at $30^{\circ} \mathrm{C}$ under photoautotrophic culture conditions. Initially, strain EFE7942 grew considerably slower than the wildtype Synechococcus 7942 strain, but gradually grew faster after subsequent re-inoculations, reaching a growth rate similar to that of the wild-type by day 13. In contrast, the GD-EFE7942 strain exhibited a slightly slower growth rate compared to the wild-type strain throughout the entire 13-day cultivation period (Fig. 6b). In terms of the ethylene production, during the first 9 days, strain GD-EFE7942 showed 3-6 times higher volumetric ethylene 


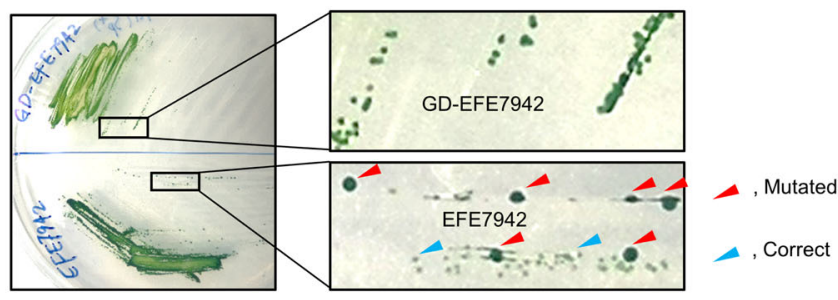

b

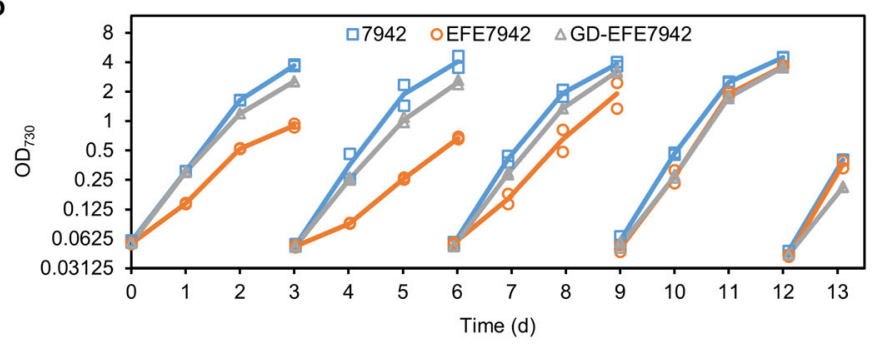

c

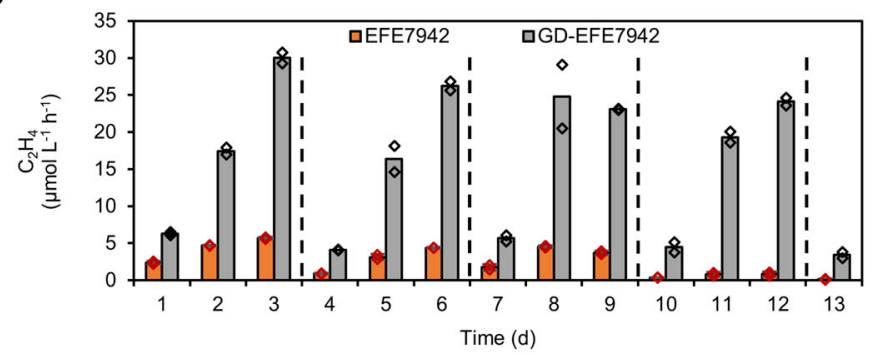

d

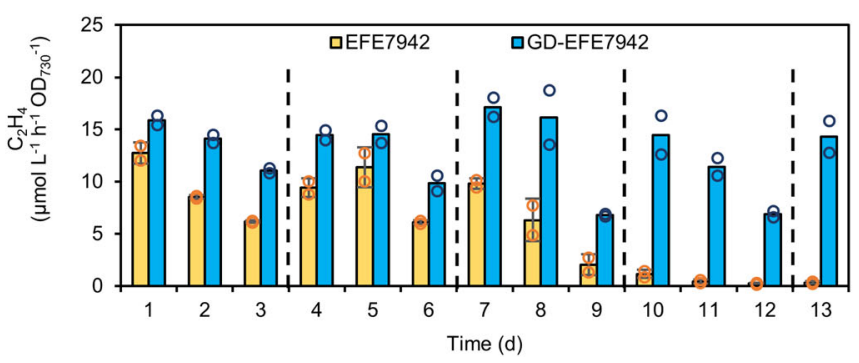

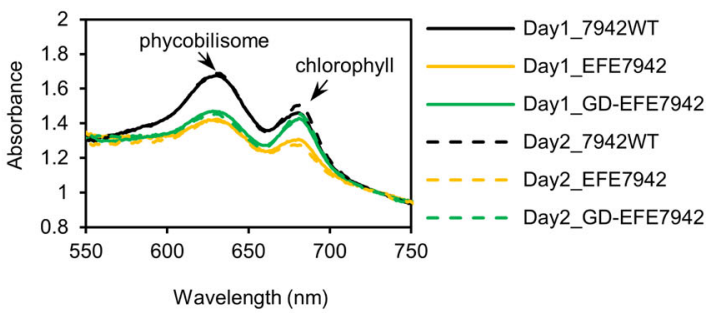

f
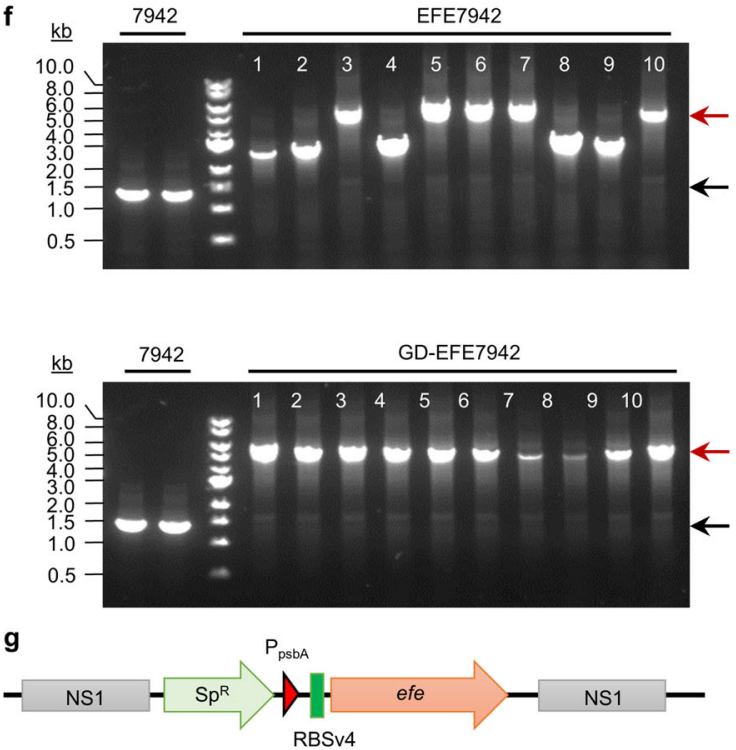

[2OG-Fe(II) oxygenase superfamily conserved region]

[2102 bp deleted in EFE7942 \#1, 2, 4, 8, 9]

I

[24 bp deleted in EFE7942 \#3, 5, 7, 10]

I

[ 1 bp deleted in EFE7942 \#6]

Fig. 6 Expression of sll1077 in Synechococcus $\mathbf{7 9 4 2}$ supports sustained high-level ethylene production. a Colonies of strains EFE7942 and GD-EFE7942 formed on agar plates at $30^{\circ} \mathrm{C}$. DNA sequencing results revealed that for strain EFE7942, the smaller colonies indicated by cyan triangles harbored the correct EFE expression cassette, while the bigger colonies denoted by red triangles harbored mutated EFE expression cassettes; for strain GD-EFE7942, colony sizes were uniform and DNA sequencing identified no mutations around the EFE expression cassette. $\mathbf{b}$ Cell growth curves in liquid cultures at $30^{\circ} \mathrm{C}$. Cultures were re-inoculated into fresh BG11 medium (supplemented with $10 \mathrm{mM} \mathrm{HEPES}, \mathrm{pH}$ 8.2, and 20 mM bicarbonate) media every 3 days. c Volumetric ethylene productivities of strains EFE7942 and GD-EFE7942. Data represent means of two independent biological replicates and are overlaid with individual data points. d Specific ethylene productivities of strains EFE7942 and GD-EFE7942. Cultures were re-inoculated every three days. Data represent means and standard deviations from two biological replicates. Data represent means of two independent biological replicates and are overlaid with individual data points. e Absorbance spectra of cultures shown in (b-d) at day 1 and day 2. Absorbance was normalized to absorbance at $730 \mathrm{~nm}$. f Two colonies of the wild-type strain 7942, ten colonies of strain EFE7942, and ten colonies of strain GD-EFE7942 were randomly picked from plates spread with diluted day-13 cultures shown in (b-d) and were subjected to colony PCR using primers flanking the efe-insertion site on the genome. Red arrows indicate the expected PCR product size for strains EFE7942 and GD-EFE7942; black arrows indicate the expected PCR product size for the wild-type 7942 strain. Representative data from two independent experiments. $\mathbf{g}$ DNA sequencing of the PCR products obtained in (f) revealed mutations of the EFE expression cassettes on the genomes of all ten randomly picked EFE7942 colonies, whereas no mutations arose within the genomic region of the EFE expression cassette in any of the ten GD-EFE7942 colonies (Supplementary Data 2). Source data underlying panels (b-d) are provided as a Source Data file.

productivities compared to strain EFE7942, with more substantial differences occurring at relatively high cell densities when guanidine accumulated to the highest levels in the culture medium (Fig. 6c and Supplementary Fig. 9). The higher volumetric ethylene productivity of GD-EFE7942 relative to EFE7942 was largely due to the improved cell growth rate and thereby higher cell density (Fig. 6b), yet was also attributed to the improved specific ethylene productivity (Fig. 6d). During the first 7 days, the specific ethylene productivity of GD-EFE7942 was 1.2-1.8 times higher than EFE7942. The difference increased to 2.6 times by day 8 , and to 3.3 times by day 9 (Fig. $6 \mathrm{~d}$ ). Starting from day 10 , both the volumetric and specific ethylene productivities of strain EFE7942 dropped substantially and declined to almost zero by day 13 (Fig. 6c, d). The guanidine 
production in the EFE7942 culture also started to drop significantly by day 10 (Supplementary Fig. 9). Absorbance spectra of the three examined cultures revealed that the abundance of phycobilisome and chlorophyll a in EFE7942 declined significantly compared to those in the wild-type strain. Although the phycobilisome level remained low in GD-EFE7942 relative to that of the wild-type strain, expression of S1l1077 restored the amount of chlorophyll a in GD-EFE7942 to a level similar to that in the wild-type strain (Fig. 6e), suggesting that degradation of guanidine partially alleviated the stress underlying loss of photosynthesis-related pigments. Further cell growth phenotyping and DNA sequencing analyses revealed that after 13 days of cultivation, approximately half the cells in the EFE7942 culture lost the entire EFE expression cassette, and the other half had DNA mutations on the genome that caused early termination of translation of EFE (Fig. 6f, g, Supplementary Fig. 10 and Supplementary Data 2). We, therefore, conclude that the initial slow growth of EFE7942 was due to the accumulation of toxic guanidine as a byproduct of making ethylene (Supplementary Fig. 9), which provided selective pressure for the cells to acquire mutations that inactivate the EFE gene and eventually rescue the growth inhibition (Fig. 6). By contrast, the GD-EFE7942 strain exhibited consistent cell growth profiles and ethylene productivities during the five consecutive batch cultures (Fig. $6 \mathrm{~b}-\mathrm{d}$ ), owing to its engineered capability to mitigate guanidine via Sll1077 (Fig. 5b and Supplementary Fig. 9) and thus enhance genomic stability (Fig. 6f). The slightly slower growth of GD-EFE7942 strain relative to the wild-type Synechococcus 7942 strain is likely attributable to the burden of expression of EFE and Sll1077 as well as redirecting metabolic fluxes from biomass synthesis to ethylene formation. In addition, the ethylene productivity of GDEFE7942 is comparable to that of the previously engineered highlevel-efe-expressing Synechocystis strains, e.g., strain PB752 in our previous work ${ }^{32}$, under the examined photoautotrophic culture conditions (Supplementary Fig. 11).

\section{Discussion}

Through comparative analysis of cyanobacterial strains, we were able to identify a guanidine-degrading enzyme, Sll1077, which breaks down guanidine to form urea and ammonium (Figs. 2c, 4, and 5). Sll1077 constitutes a guanidine-degradation pathway that does not require ATP, and is completely different from the recently identified guanidine carboxylation pathway ${ }^{5,13}$ (Fig. 4h). Guanidine carboxylase catalyzes the carboxylation of guanidine using ATP as the driving force. However, the product compound carboxyguanidine is unstable and is readily hydrolyzed to form guanidine and $\mathrm{CO}_{2}$ in water, forming an ATP-consuming futile cycle $^{13}$. The efficiency of the guanidine carboxylation pathway largely depends on the rate of removal of carboxyguanidine by the carboxyguanidine deiminase which converts carboxyguanidine to ammonium and allophanate ${ }^{13}$. In contrast, the guanidinedegrading enzyme Sll1077 investigated in this study acts as a deiminase and is able to, without consuming ATP, directly convert guanidine to urea (Fig. $4 \mathrm{~b}-\mathrm{e}$ and Supplementary Fig. 6), which could be further degraded into $\mathrm{CO}_{2}$ and ammonium by the urease in most cyanobacterial species, including Synechocystis $6803^{29}$ (Fig. 4h). Therefore, the Sll1077-associated guanidinedegradation pathway seems more energy-efficient compared to the guanidine carboxylation pathway. The catalytic efficiency of Sll1077, as calculated in the current study (Fig. 4g), seems much lower than some high-efficiency enzymes, such as the agmatinases in $E$. coli and in Anabaena ${ }^{33}$. It explains why guanidine was accumulated in and out of efe-expressing cyanobacterial cells despite expression of the guanidinase Sll1077 (Supplementary Fig. 9) ${ }^{27}$. However, we realize that the low catalytic efficiency of guanidinase estimated in the current study is consistent with the fact that biodegradation of guanidine in nature is such a slow process that guanidine has been commonly utilized as a slowrelease fertilizer in agriculture ${ }^{2,7}$.

Sll1077 represents a class of guanidine-degrading (i.e., guanidinase) enzymes. It was recently uncovered that the main arginine utilization pathway in cyanobacteria is the arginine dihydrolase-mediated route ${ }^{34,35}$. Besides, cyanobacteria employ the agmatinase-mediated pathway for biosynthesis of polyamines $^{33}$. Both S1l1077 and S1l0228 in Synechocystis 6803 have been annotated as putative agmatinases since they both have the conserved regions of the agmatinase/arginase superfamily proteins $^{14,15}$. However, their protein sequences show $<25 \%$ identities (Supplementary Fig. 12), and we found through protein BLAST that Sll0228 (44\% positive hit) is more similar than Sll1077 (37\% positive hit) to the biochemically characterized cyanobacterial agmatinase from Anabaena ${ }^{33}$. A recent study also showed that deletion of sll0228 rather than sll1077 significantly impairs the utilization of arginine in Synechocystis $6803^{35}$, which is consistent with a previous report that the agmatinase activity in Synechocystis 6803 is mostly attributed to Sll0228 36 . Despite the enigmatic role of S111077, from a bioinformatics approach it was found that the expression of S1l1077 and its analogs (previously annotated to encode agmatinase or arginase enzymes) in a wide range of microorganisms is under the control of guanidine riboswitches (Fig. 2a, b and Supplementary Data 3) ${ }^{5,8,9}$. These genes often form operons with other genes, such as hypA, hypB, SsuA_fam (sll1080 in Synechocystis 6803), TM_PBP2 (sll1081 in Synechocystis 6803), and ABC_NrtD_SsuB (sll1082 in Synechocystis 6803) (Supplementary Data 3$)^{\overline{5}}$. The expression levels of these genes were all enhanced in guanidine-producing Synechocystis strains compared to wild-type controls according to our proteomic data (Supplementary Data 1) and results from a previous transcriptomic study ${ }^{37}$, which is consistent with the modulation mechanism of guanidine riboswitches ${ }^{5}$. Taken together, these results suggest that Sll1077 may be evolved for a function that is completely different from the degradation of arginine or agmatine. Our findings that Sll1077 is able to degrade guanidine and that it prefers guanidine rather than agmatine as the substrate is consistent with the prediction that its expression is under the control of a guanidine riboswitch (Figs. $2 \mathrm{a}, \mathrm{b}$ and $5 \mathrm{c}, \mathrm{d})^{5}$, which suggests that S1l1077 and possibly its analogs are evolved for the degradation of guanidine. It is likely that guanidine, formed either biologically or abiotically, is present in the natural environment where Synechocystis 6803 lives, and possessing a guanidinaseencoding gene might have provided a survival advantage to this species. Running a protein BLAST for the Sll1077 peptide sequence (https://blast.ncbi.nlm.nih.gov/) returned over a thousand hits with $>50 \%$ sequence identities, all of which have been annotated as arginase/agmatinase family proteins (Supplementary Data 4 ). Whether these proteins possess the capability to degrade guanidine needs to be studied in the future.

Guanidine causes a disorder of pigment metabolism in cyanobacterial cells. Guanidine is known to interact with the peptide backbone and side chains of amino acids, and serves as a protein denaturant when applied at high concentrations $(2-6 \mathrm{M})^{1,38,39}$. At concentrations insufficient to completely unravel the protein structure, guanidine could also be detrimental to biomacromolecules. For example, relatively small amounts of guanidine could trigger unfolding of the active site of ribonuclease A and thereby inactivate the enzyme activity and facilitate the proteolysis process ${ }^{40}$. Another example is that millimolar guanidine could significantly inhibit ammonium nitrification in the nitrifying bacteria in soil ${ }^{41}$. In our study, the presence of guanidine in the culture medium, either from exogenous or endogenous sources, severely inhibited cell growth of wild-type Synechococcus 7942 
and the Synechocystis $\Delta$ sll1077 strain (Figs. 1a, b, 2d, e, 5a, and 6a, b). These guanidine-sensitive strains exhibited remarkably slow degradation of their light-harvesting components under nitratedeprived and guanidine-supplemented culture conditions (Figs. 1a and 2e, f). Under nitrogen-poor culture conditions, cyanobacterial cells typically undergo a chlorosis process that involves degrading their phycobiliproteins and chlorophyll as a nitrogen source to support cell growth while simultaneously downregulating photosynthesis in order to reduce the generation of damaging oxygen radicals ${ }^{26}$. Impaired cell growth and retarded pigment degradation in both cultures of Synechocystis 6803+ and $\Delta$ sll1077 + on day 1 (Fig. $2 \mathrm{~d}-\mathrm{f}$ ) suggested that induction of nitrogen chlorosis was disrupted by guanidine under the examined culture conditions. Furthermore, the biosynthesis of phycobiliproteins and chlorophyll was severely inhibited in strain Synechococcus EFE7942, whereas the biosynthesis of chlorophyll was restored through heterologous expression of Sll1077 in strain GD-EFE7942 (Fig. 6e), which provided additional evidence that guanidine hampers the biosynthesis and remodeling of photosynthesis-related pigments in cyanobacteria.

While the wild-type Synechococcus 7942 is sensitive to guanidine and fails to accommodate the high-level expression of EFE (Figs. 1a, b, 5a, and 6), our discovery of the guanidine-degrading activity of Sll1077 was leveraged to generate a derivative strain of Synechococcus 7942 that exhibits enhanced genomic stability and stable high-level production of ethylene in prolonged culture, which has not been achieved in prior studies (Fig. 6 and Supplementary Fig. 8) ${ }^{23-25,42}$. It is noteworthy that co-expression of Sll1077 with EFE substantially attenuates, but does not completely eliminate, the accumulation of guanidine in cultures of the engineered Synechococcus GD-EFE7942 strain (Supplementary Fig. 9). Although this seems already sufficient for rendering genomic stability and sustained stable ethylene production in GD-EFE7942 (Fig. 6 and Supplementary Figs. 8 and 10), as well as the Synechocystis strain $\mathrm{PB} 752^{27}$, it could be possible to obtain a more efficient guanidine-degrading enzyme, perhaps through directed evolution of S111077, in order to achieve faster degradation of guanidine and further reduce its toxicity in the future. In summary, this study has advanced our understanding of the biological routes of guanidine metabolism in nature and has demonstrated a useful approach for enhancing the biosynthesis of ethylene by reducing the toxic byproduct guanidine in engineered microorganisms.

\section{Methods}

Bacterial strains and growth conditions. E. coli NEB5a (New England BioLabs, MA, USA) served as the microbial host for cloning and maintaining all recombinant plasmids, and was routinely grown in LB medium. Synechocystis and Synechococcus strains were typically grown in a modified chemically defined BG11 medium (mBG11) ${ }^{27}$. Briefly, one liter of mBG11 medium contains the following components in deionized water: $1.5 \mathrm{~g} \mathrm{NaNO}_{3}, 75 \mathrm{mg} \mathrm{MgSO}_{4} \cdot 7 \mathrm{H}_{2} \mathrm{O}, 36 \mathrm{mg}$ $\mathrm{CaCl}_{2} \cdot 2 \mathrm{H}_{2} \mathrm{O}, 6.6 \mathrm{mg}$ citric acid $\cdot \mathrm{H}_{2} \mathrm{O}, 11.2 \mathrm{mg}$ EDTA $\cdot \mathrm{Na}_{2}, 20 \mathrm{mg} \mathrm{Na} \mathrm{CO}_{3}, 30.5 \mathrm{mg}$ $\mathrm{K}_{2} \mathrm{HPO}_{4}, 6 \mathrm{mg}$ ferric ammonium citrate, $2.86 \mathrm{mg} \mathrm{H} \mathrm{BO}_{3}, 1.81 \mathrm{mg} \mathrm{MnCl}_{2} \cdot 4 \mathrm{H}_{2} \mathrm{O}$, $0.22 \mathrm{mg} \mathrm{ZnSO} \cdot 7 \mathrm{H}_{2} \mathrm{O}, 0.39 \mathrm{mg} \mathrm{Na} \mathrm{MoO}_{4} \cdot 2 \mathrm{H}_{2} \mathrm{O}, 0.08 \mathrm{mg} \mathrm{CuSO} \cdot 5 \mathrm{H}_{2} \mathrm{O}$, and $0.04 \mathrm{mg} \mathrm{CoCl} \cdot 6 \mathrm{H}_{2} \mathrm{O}$. $\mathrm{N}$-tris(hydroxymethyl)methyl-2-aminoethanesulfonic acid (TES, pH adjusted to 8.2 by $\mathrm{NaOH}$ ) and $\mathrm{NaHCO}_{3}$ were supplemented into BG11 medium to final concentrations of $20 \mathrm{mM}$ and $100 \mathrm{mM}$, respectively, unless otherwise specified. The medium was filtered through sterile $0.22-\mu \mathrm{m}$ membranes before use. Cyanobacterial liquid cultures were grown under constant light of about $50 \mu \mathrm{E} \mathrm{m}^{-2} \mathrm{~s}^{-1}$ on a rotary shaker at $150 \mathrm{rpm}$ and $30^{\circ} \mathrm{C}$ in a Percival chamber (Percival Scientific, Inc., IA, USA) aerated with $5 \% \mathrm{CO}_{2}$ unless otherwise specified. When cyanobacteria were grown on solid medium, $10 \mathrm{mM}$ TES-NaOH (pH8.2), $3 \mathrm{~g} \mathrm{~L}^{-1}$ thiosulfate and $15 \mathrm{~g} \mathrm{~L}^{-1}$ agar were supplemented to the mBG11 medium, and sterilized by autoclaving at $121^{\circ} \mathrm{C}$ for $30 \mathrm{~min}$. When appropriate, antibiotics were added to the solid medium to the following final concentrations: $50 \mathrm{mg} \mathrm{L}^{-1}$ for spectinomycin and $7 \mathrm{mg} \mathrm{L}^{-1}$ for chloramphenicol, respectively.

Construction of recombinant plasmids. All enzymes and cloning kits were purchased from New England Biolabs, MA, USA, unless otherwise specified. Kits for DNA purification were purchased from Qiagen, MD, USA. Plasmid pPB305 was constructed by PCR amplification of the DNA fragments of sll1077U, sll1077D, and gene cat, and Gibson Assembly into plasmid pBlueScript II SK (+) which was digested with KpnI and SacI. The DNA fragment containing gene sll1077 was PCR amplified from the genomic DNA of Synechocystis 6803 and inserted between the NdeI and XhoI restriction sites on pET30a $(+)$, so that Sll1077 will be tagged with $6 \mathrm{xHis}$, resulting in plasmid pPB300. pPB306 was constructed by PCR amplifying sll1077-His from pPB300 and inserting it between the NdeI and SalI restriction sites on pSCPTH (Wang, 2013) using Gibson Assembly Kit. pPB306d was constructed by deleting the lac promoter region on the pBluescript vector backbone via digesting pPB306 with SacI and SapI restriction enzymes and then blunt-ended using T4 DNA polymerase and self-ligated using Quick DNA ligase. pPB307, pPB308, pPB309, pPB310, and pPB311 were constructed by replacing the RBS in pPB306d using the Site-Directed Mutagenesis Kit. pPB312 was constructed by deleting the CTCGAG (XhoI) nucleotides between the sll1077 coding sequence and the 6xHis tag on plasmid pPB309. pPB316 was constructed by inserting the $r r n B T 1 T 2$ terminator (from E. coli NEB5a) downstream of sll1077 on pPB312. pPB312 was digested with SalI, dephosphorylated, and then assembled with the terminator rrnBT1T2 using Gibson Assembly Kit. The map and DNA sequence of pPB316 are included in Supplementary Information. pPB313 was constructed by deleting the 6xHis tag and CTCGAG (XhoI) between the sll1077 coding sequence and stop codon TAA of pPB309. pPB317 was constructed by inserting rrnBT1T2 downstream of sll1077 on pPB313, which was digested with SalI and dephosphorylated, using the Gibson Assembly Kit. Plasmid To express the efe gene in Synechococcus 7942, $1.43 \mathrm{~kb}$ of the BbvCI/XhoI fragment containing psbAp::efe-FLAG from pJU158 was blunt-ended and ligated to the SmaI site of the neutral site 1 vector pAM1303, resulting in pEFE-FLAG-NS1. To overexpress the sll1077 gene in Synechococcus 7942, $1.69 \mathrm{~kb}$ of the BamHI/SalI fragment harboring the sll1077 expression cassette from pPB317 was cloned into the BamHI/SalI site of a neutral site 4-targeting vector pCX0104-LuxAB-FT ${ }^{43}$ to generate pGD7942-NS4. The DNA sequence of genes of interest was all confirmed by DNA sequencing. All plasmids used in this study are listed in Supplementary Table 1 and DNA sequences of representative recombinant DNA constructs are included in Supplementary Data 5. Primers used in constructing all plasmids are detailed in Supplementary Table 2.

Genome engineering of cyanobacteria. Transformation of Synechocystis was accomplished via natural transformation ${ }^{44}$. Briefly, the wild-type Synechocystis 6803 strain was grown in mBG11 medium until the $\mathrm{OD}_{730}$ reached $\sim 0.4$. Then, $2.5 \mathrm{~mL}$ of the culture was condensed to about $0.2 \mathrm{~mL}$ via centrifugation and resuspension with the same culture medium. Cells were transferred into a $1.5-\mathrm{mL}$ Eppendorf tube and mixed with 1-2 $\mu$ g DNA of integration plasmid. The sample was incubated under low light for about $5 \mathrm{~h}$, and mixed once in the middle of the incubation. Cells were then spread onto BG11 plates supplemented with appropriate antibiotics and incubated at $30^{\circ} \mathrm{C}$ under about $25 \mu \mathrm{E} \mathrm{m}^{-2} \mathrm{~s}^{-1}$. Colonies usually appear within 1-2 weeks. Strains PB805W- PB812W, PB816W, and PB817W were constructed by transforming wild-type Synechocystis 6803 with integration plasmids pPB305-pPB312, pPB316, and pPB317. Transformation of Synechococcus 7942 was completed following a natural transformation protocol ${ }^{45}$. Briefly, 5-10 mL of log-phase cyanobacterial cells were centrifuged at $3000 \times g$ for $5 \mathrm{~min}$. Then, the cell pellet was washed with $10 \mathrm{~mL}$ of $10 \mathrm{mM} \mathrm{NaCl}$ followed by centrifugation and disposal of the supernatant. Cells were resuspended with $0.3 \mathrm{~mL}$ of mBG11 medium and were mixed with $1 \mu \mathrm{L}$ of purified DNA (about $0.1-0.3 \mu \mathrm{g}$ ), followed by incubation with gentle shaking in darkness overnight. $0.1 \mathrm{~mL}$ of transformation mix (diluted when necessary) was spread onto BG11 plates supplemented with appropriate antibiotics and incubated at $30^{\circ} \mathrm{C}$ under about $25 \mu \mathrm{E} \mathrm{m}^{-2} \mathrm{~s}^{-1}$. Colonies typically appear within 1-2 weeks. Transformation of Synechococcus 7942 with integration plasmids pEFE-FLAG-NS1 or pGD7942-NS4 resulted in strain EFE7942 and GD7942, respectively. The efe expression cassette was PCR amplified from the genomic DNA of EFE7942 strain using primers NS15 and NS16, and inserted into the neutral site 1 of the genome of Synechococcus GD7942, resulting in strain GD-EFE7942. The complete segregation of genomes was verified via colony PCR, followed by DNA sequencing of the PCR products amplified using primers (listed in Supplementary Table 2) flanking the modified regions of the cyanobacterial genomes. DNA sequencing was performed by GENEWIZ (South Plainfield, NJ, USA). The strains used in this study are listed in Supplementary Table 1.

SDS-PAGE and western blotting. When the $\mathrm{OD}_{730}$ of cyanobacterial culture reached $0.5-1.0, \sim 5 \mathrm{OD}_{730} \mathrm{~mL}$ (i.e., $10 \mathrm{~mL}$ if the $\mathrm{OD}_{730}$ of the culture equals 0.5 ) of cells were collected via centrifugation at $3220 \times g, 24^{\circ} \mathrm{C}$ for $5 \mathrm{~min}$ and removal of supernatants. The cell pellets were stored at $-80^{\circ} \mathrm{C}$ until use. Upon running SDSPAGE, cells were resuspended with $0.5 \mathrm{~mL}$ of cold $0.1 \mathrm{M}$ potassium phosphate buffer (pH 7.0) supplemented with DTT $(0.2 \mathrm{mM})$ and Halt Protein Inhibitor Cocktail (Thermo Fisher Scientific, MA, USA), and mixed with $0.2 \mathrm{~g}$ of $0.1-\mathrm{mm}$ diameter acid-washed glass beads, and then subjected to bead-beating at $4{ }^{\circ} \mathrm{C}$ for 5 min using the Digital Disruptor Genie (Scientific Industries, Inc., NY, USA). The cell lysate was centrifuged at $4{ }^{\circ} \mathrm{C}, 18,000 \times g$ for $10 \mathrm{~min}$, and then the supernatant containing soluble proteins was transferred into a new Eppendorf tube placed on ice. The protein concentrations were estimated using the Bradford assay (Thermo Fisher Scientific, MA, USA). Then, $2.5 \mu \mathrm{g}$ of protein from each sample was mixed 
with $2 \times$ SDS-PAGE sample buffer $(950 \mu$ Bio-Rad $2 \times$ Laemmli Sample Buffer $+50 \mu \mathrm{l}$ BME) in a PCR tube and incubated at $99^{\circ} \mathrm{C}$ for 5 min using a thermocycler. Samples were then loaded onto Mini-PROTEAN ${ }^{\oplus}$ TGX Stain-Free ${ }^{\text {twx }}$ precast gels (Bio-Rad Laboratories, CA, USA), and electrophoresis was conducted at $150 \mathrm{~V}$ for about $45 \mathrm{~min}$. Gels were imaged using UV excitation in a FluorChem Q imager (ProteinSimple, CA, USA).

Western blotting was conducted using Pierce ${ }^{\mathrm{m}} \mathrm{G}$ G Fast Blotter (Thermo Fisher Scientific, MA, USA). HisProbe ${ }^{m}$-HRP Conjugate (Catalog number: 15165, Thermo Fisher Scientific, MA, USA) was used as the probe (at 1:500 dilution) to detect the Sll1077-His. In total, 2 mL SuperSignal ${ }^{\mathrm{TM}}$ West Dura Extended Duration Substrate (Catalog number: 34075, Thermo Fisher Scientific, MA, USA) was added to each blot and incubated for $5 \mathrm{~min}$ before the chemiluminescent blots were imaged using FluorChem Q imager (ProteinSimple, CA, USA).

In vitro enzyme activity assay. His-tagged Sll1077 i.e., Sll1077-His, was first purified from Synechocystis PB816W. PB816W was grown in $250 \mathrm{~mL}$ mBG11 medium under $120 \mu \mathrm{E} \mathrm{m}^{-2} \mathrm{~s}^{-1}$ until an $\mathrm{OD}_{730}$ of about 2 , and then cells were harvested via centrifugation at $4700 \times g, 24^{\circ} \mathrm{C}$ for $10 \mathrm{~min}$ followed by removal of supernatants. The cell pellets were stored at $-80^{\circ} \mathrm{C}$. Cells were subsequently resuspended with $10 \mathrm{~mL}$ of cold $20 \mathrm{mM}$ Tris $\cdot \mathrm{HCl}(\mathrm{pH}$ 7.5) containing $1 \mathrm{mM}$ DTT and $1 \times$ Halt Protein Inhibitor Cocktail (Thermo Fisher Scientific, MA, USA), and lysed by sonication in an ice-water bath via 100 cycles of 5-s-on-5-s-off. The cell lysate was centrifuged at $4{ }^{\circ} \mathrm{C}, 17,000 \times g$ for $30 \mathrm{~min}$. Then, the supernatant containing soluble proteins was loaded onto His GraviTrap (GE Healthcare) column to purify Sll1077-His following the user manual. The Sll1077-His was eluted with an elution buffer containing $20 \mathrm{mM}$ Tris $\cdot \mathrm{HCl}$ (pH7.5), $500 \mathrm{mM} \mathrm{NaCl}$ and $500 \mathrm{mM}$ immidizole. The eluted samples were dialyzed against a dialysis buffer that contains $20 \mathrm{mM}$ Tris $\cdot \mathrm{HCl}(\mathrm{pH} 7.5), 50 \mathrm{mM} \mathrm{NaCl}$ and $1 \mathrm{mM} \mathrm{MnCl}_{2}$ at room temperature for $2 \mathrm{~h}$ and then dialyzed against fresh dialysis buffer at $4{ }^{\circ} \mathrm{C}$ over night. The protein concentration was determined using a Bradford assay kit.

Guanidine was added into $1.6 \mathrm{~mL}$ of reaction buffer (the same as the above dialysis buffer) to a series of final concentrations, i.e., $0,0.25,0.5,1,1.5,2.5,5$, and $10 \mathrm{mM}$. The reaction mixes were incubated at $30^{\circ} \mathrm{C}$ in a water bath for about $15 \mathrm{~min}$ before $0.2 \mathrm{~mL}$ of purified Sll1077-His $\left(0.67 \mathrm{mg} \mathrm{mL}^{-1}\right)$ or BSA $\left(0.67 \mathrm{mg} \mathrm{mL}^{-1}\right)$ was added to initiate the reaction. In some experiments, ATP was added into the reaction mix to a final concentration of $1 \mathrm{mM}$. The reaction mixes were incubated at $30^{\circ} \mathrm{C}$ in a water bath for $3 \mathrm{~h}$, and $0.5 \mathrm{~mL}$ was sampled at 0,1 , and $3 \mathrm{~h}$. Immediately after being sampled, samples were quenched with $50 \mu \mathrm{L} 2 \mathrm{~N} \mathrm{HCl}$, and were neutralized with $50 \mu \mathrm{L} 2 \mathrm{~N} \mathrm{NaOH}$ after all samples were collected. Samples were stored at $-20^{\circ} \mathrm{C}$ until further analysis.

For measuring urea in the samples, $150 \mu \mathrm{L}$ of each sample was mixed with $600 \mu \mathrm{L}$ methanol, vortexed, and then $150 \mu \mathrm{L}$ chloroform was added, vortexed, and then $450 \mu \mathrm{L}$ water was added, vortexed, followed by centrifugation at $17,000 \times g$ for $2 \mathrm{~min}$. The aqueous phase $(\sim 1.2 \mathrm{~mL})$ was transferred into a clean Eppendorf tube, air-dried overnight and then lyophilized before being mixed with $35 \mu \mathrm{L}$ of pyridine and $50 \mu \mathrm{L}$ of MTBSTFA $+1 \%$ TBDMCS (Regis Technologies, Inc., IL, USA). The derivatization reaction mix was incubated at $70^{\circ} \mathrm{C}$ for $30 \mathrm{~min}$. A series of concentrations of urea standards were dissolved in the in vitro enzyme assay buffer, lyophilized and derivatized side by side with the enzyme assay samples in order to establish a calibration curve to quantify the urea. The derivatized samples were centrifuged at $17,000 \times g$, room temperature for $5 \mathrm{~min}$, and then $1 \mu \mathrm{L}$ the supernatants were analyzed on GC-MS using a method adapted from a previous study ${ }^{46}$. Briefly, GC-MS was performed using an Agilent 7890 gas chromatograph (GC) connected to an Agilent 5977 A mass spectrometer (MS). The GC was equipped with a HP-5ms column $(2 \times 15 \mathrm{~m} \times 0.25 \mathrm{~mm}$ i.d., $0.25-\mu \mathrm{m}$ film thickness; J\&W Scientific, Cat. No. 19091S-431). The injection volume was $1 \mu \mathrm{L}$ and all samples were run in splitless mode with an inlet temperature of $270^{\circ} \mathrm{C}$. The helium flow rate was set to $1 \mathrm{~mL} \mathrm{~min}^{-1}$. The GC oven temperature was held at $80^{\circ} \mathrm{C}$ for $1 \mathrm{~min}$, ramped at $20^{\circ} \mathrm{C} \mathrm{min}^{-1}$ to $140^{\circ} \mathrm{C}$, and then ramped at $4^{\circ} \mathrm{C} \mathrm{min}^{-1}$ to $174^{\circ} \mathrm{C}$, and then ramped at $40^{\circ} \mathrm{C} \mathrm{min}^{-1}$ to $285^{\circ} \mathrm{C}$. A 3-min column backflushing was performed after each run at a post run temperature of $315^{\circ} \mathrm{C}$. Mass spectra were obtained in scan mode over the range $140-595 \mathrm{~m} / \mathrm{z}$. MS source temperature was $230^{\circ} \mathrm{C}$, and MS quad temperature was $150^{\circ} \mathrm{C}$. Agilent MassHunter Workstation GC/MS Data Acquisition Version 10.0.368 was used for collecting GC-MS data.

For HPLC quantification of guanidine, $100 \mu \mathrm{L}$ samples were subjected to methanol/chloroform extraction and air-dried as stated above, and then resuspended with $1 \mathrm{~mL}$ of deionized water before being analyzed using the method described below.

For analysis of ammonium, a $300-\mu \mathrm{L}$ sample was diluted by $\mathrm{dH}_{2} \mathrm{O}$ to $1.5 \mathrm{~mL}$ and then analyzed using an Ammonia Gas Sensing Electrode (Cat. No. 9512BNWP, Thermo Fisher Scientific, MA, USA) according to the manual.

In vitro substrate preference assay for Sll1077. Synechococcus 7942 and GD7942 strains were grown in 250-mL flasks each containing $60 \mathrm{~mL}$ mBG11 medium supplemented with $50 \mathrm{mM} \mathrm{NaHCO}$ on a rotary shaker at $130 \mathrm{rpm}$, under $1 \% \mathrm{CO}_{2}, 60 \mu \mathrm{E} \mathrm{m}^{-2} \mathrm{~s}^{-1}$ until $\mathrm{OD}_{730}$ reached about 1.5. Then $60 \mathrm{OD}_{730} \mathrm{~mL}$ of cells were harvested and centrifuged at $4700 \times g, 24^{\circ} \mathrm{C}$ for $10 \mathrm{~min}$. The supernatants were discarded, and the cell pellets were kept at $-80^{\circ} \mathrm{C}$ until use. Subsequently, cell pellets were resuspended with $1 \mathrm{~mL} 100 \mathrm{mM}$ Tris $\cdot \mathrm{HCl}(\mathrm{pH} 8.0)$ containing $1 \mathrm{mM}$ DTT and $1 \times$ Halt Protein Inhibitor Cocktail (Thermo Fisher Scientific, MA, USA), and lysed by sonication in an ice-water bath. The lysates were then centrifuged at $4^{\circ} \mathrm{C}, 17,000 \times g$ for $30 \mathrm{~min}$. Then the cell extract (supernatants) were used for the following in vitro assay: $1.54 \mathrm{~mL} 100 \mathrm{mM}$ Tris $\cdot \mathrm{HCl}(\mathrm{pH} 8.0), 20 \mu \mathrm{L} \mathrm{MnCl}_{2}, 20 \mu \mathrm{L}$ $\mathrm{NH}_{4} \mathrm{Cl}, 400 \mu \mathrm{L}$ cell extract, and $20 \mu \mathrm{L} 500 \mathrm{mM}$ guanidine $\cdot \mathrm{HCl}$ or agmatine $\cdot \mathrm{HCl}$ (with a total reaction volume of $2 \mathrm{~mL}$ ). All the components but the cell extract in each reaction mix were mixed together and incubated in a $30^{\circ} \mathrm{C}$ water bath for about $15 \mathrm{~min}$ before the cell extract was added into the reaction mix to start the assay. In the control experiments, cell extracts were replaced by the $400 \mu \mathrm{L} 100 \mathrm{mM}$ Tris $\cdot \mathrm{HCl}(\mathrm{pH} 8.0)$ containing $1 \mathrm{mM}$ DTT and $1 \times$ Halt Protein Inhibitor Cocktail During incubation, $0.5 \mathrm{~mL}$ of sample was taken from the reaction mixes at 0,2 , and $12 \mathrm{~h}$ time points, and were immediately mixed with $50 \mu \mathrm{L} 2 \mathrm{~N} \mathrm{HCl}$ to quench any enzymatic activity. $50 \mu \mathrm{L} 2 \mathrm{~N} \mathrm{NaOH}$ was then added the samples to neutralize the $\mathrm{pH}$ followed by storage at $-20^{\circ} \mathrm{C}$. After all samples were collected, $150 \mu \mathrm{L}$ of each sample was used for quantification of urea using GC-MS and another aliquot of $150 \mu \mathrm{L}$ was used for quantification of guanidine and agmatine using HPLC. The samples were subsequently processed following a similar protocol as described in the previous section.

Quantification of guanidine and agmatine using HPLC. Guanidine was quantified using a protocol modified from a previous method ${ }^{27}$. Briefly, guanidine hydrochloride and agmatine standard solutions and biological samples were passed through $0.2-\mu \mathrm{m}$ diameter membrane filters and then were analyzed using an Agilent 1200 Series HPLC (Agilent, USA) equipped with a Multi-Wavelength Detector and a set of Dionex IonPac ${ }^{\mathrm{TM}} \mathrm{CS} 14$ cation-exchange guard $(4 \mathrm{~mm} \times 50$ $\mathrm{mm})$ and analytical columns $(4 \times 250 \mathrm{~mm}$; Thermo Fisher Scientific, MA, USA). The column temperature was held at $30^{\circ} \mathrm{C}$. The mobile phase was $20 \mathrm{mM}$ methanesulfonic acid dissolved in $5 \%$ acetonitrile in water, and it was pumped through the column at a constant flow rate of $1.0 \mathrm{~mL} \mathrm{~min}^{-1}$ for $30 \mathrm{~min}$. The sample injection volume was $50 \mu \mathrm{L}$. Guanidine and agmatine were eluted at around $3.7 \mathrm{~min}$ and $7.9 \mathrm{~min}$, respectively, and were monitored by their absorbance at $195 \mathrm{~nm}$ using the Agilent ChemStation software Rev. B.04.01 SP1.

Guanidine-tolerance and -degradation test. For the guanidine-tolerance test, Synechococcus strains were grown in $20 \mathrm{~mL}$ mBG11 medium supplemented with $0-1 \mathrm{mM}$ guanidine and $50 \mathrm{mM} \mathrm{NaHCO}$. For the guanidine-degradation test, Synechocystis strains were grown in $10 \mathrm{~mL}$ mBG11 free of nitrate while supplemented with $50 \mathrm{mM} \mathrm{NaHCO}$ and $5 \mathrm{mM}$ or $1 \mathrm{mM}$ guanidine chloride, under constant light of $50 \mu \mathrm{E} \mathrm{m}^{-2} \mathrm{~s}^{-1}$ on a rotary shaker at $150 \mathrm{rpm}$ and $30^{\circ} \mathrm{C}$. Every day, $1 \mathrm{~mL}$ of culture was sampled for reading $\mathrm{OD}_{730}$ and then transferred into an Eppendorf tube and centrifuged at $17,000 \times g$ at room temperature for $2 \mathrm{~min}$. The supernatants were stored at $-20^{\circ} \mathrm{C}$ for later analysis of guanidine.

Production of ethylene from engineered Synechococcus strains. The Synechococcus EFE7942, GD-EFE7942, and WT (a negative control) strains were grown in mBG11 supplemented with $10 \mathrm{mM}$ HEPES-NaOH (pH 8.2) and $20 \mathrm{mM} \mathrm{NaHCO}_{3}$ at $35^{\circ} \mathrm{C}$ until $\mathrm{OD}_{730}$ reached $\sim 1.0$. Subsequently, each strain was inoculated into $50 \mathrm{~mL}$ fresh medium with an initial $\mathrm{OD}_{730}$ of about 0.05 , and grown under continuous light of $100 \mu \mathrm{E} \mathrm{m}^{-2} \mathrm{~s}^{-1}$ at $30^{\circ} \mathrm{C}$ aerated with $1 \% \mathrm{CO}_{2}$ at a rate of $50 \mathrm{~mL} \mathrm{m^{-1 }}$. Every day, $2 \mathrm{~mL}$ of culture was sampled for ethylene productivity assay, measurement of $\mathrm{OD}_{730}$ and guanidine analysis. After every 3 days of cultivation, appropriate volumes of cultures were centrifuged and resuspended with $50 \mathrm{~mL}$ fresh medium to an initial $\mathrm{OD}_{730}$ of about 0.05 .

Measurement of ethylene produced from cyanobacteria. One milliliter cyanobacterial culture was transferred into a $17-\mathrm{mL}$ glass test tube, sealed immediately with a rubber stopper, and incubated under $100 \mu \mathrm{E} \mathrm{m}^{-2} \mathrm{~s}^{-1}$ at $30{ }^{\circ} \mathrm{C}$ with shaking. After $3 \mathrm{~h}$ of incubation, $250 \mu \mathrm{L}$ gas was sampled from the headspace of the test tube using a sample-lock syringe and injected into the Shimadzu GC-2010 system equipped with a flame ionization detector (FID) and a RESTEK column (length, $30.0 \mathrm{~m}$; inner diameter, $0.32 \mathrm{~mm}$; film thickness, $5 \mu \mathrm{m}$ ). The GC-FID was operated under the following conditions: carrier gas, helium; inlet temperature, $200^{\circ} \mathrm{C}$; split ratio, 25; inlet total flow, $40.4 \mathrm{~mL} \mathrm{~min}^{-1}$; Pressure, $79 \mathrm{kPa}$; column flow, $1.53 \mathrm{~mL} \mathrm{~min}^{-1}$; linear velocity, $32.1 \mathrm{~cm} \mathrm{~s}^{-1}$ (Flow Control Mode); purge flow, $0.5 \mathrm{~mL} \mathrm{~min}^{-1}$; column temperature, $130^{\circ} \mathrm{C}$; equilibration time, $2 \mathrm{~min}$; hold time, $2 \mathrm{~min}$; FID temperature, $200^{\circ} \mathrm{C}$; sampling rate, $40 \mathrm{~ms}$; stop time, $2 \mathrm{~min}$; FID makeup gas, He; FID makeup flow, $30 \mathrm{~mL} \mathrm{~min}^{-1}$; $\mathrm{H} 2$ flow, $40 \mathrm{~mL} \mathrm{~min}^{-1}$; airflow: $400 \mathrm{~mL} \mathrm{~min}^{-1}$. The standard curve for calibrating ethylene concentrations was generated using the ethylene calibration gas purchased from GASCO (Oldsmar, FL, USA). The GC-FID data collection and analysis were operated using Shimadzu LabSolutions Lite software Release 5.52 .

Shotgun proteomics. Synechocystis 6803 and the ethylene-producing JU547 were inoculated into $3 \times 50 \mathrm{~mL}$ mBG11 with an initial $\mathrm{OD}_{730}$ of 0.1 . When $\mathrm{OD}_{730}$ reached about $0.5,60 \mathrm{OD}_{730} \mathrm{~mL}$ cells were collected via centrifugation at $3220 \times g$, $4^{\circ} \mathrm{C}$ for $5 \mathrm{~min}$. The cell pellets were washed with $25 \mathrm{~mL}$ cold wash buffer $(50 \mathrm{mM}$ Tris $\cdot \mathrm{HCl}, \mathrm{pH} 8.0$ and $10 \mathrm{mM} \mathrm{CaCl}$ ) and centrifuged again, followed by washing with $20 \mathrm{~mL}$ and $1 \mathrm{~mL}$ washing buffer. The supernatants were discarded and cells were frozen at $-80^{\circ} \mathrm{C}$. Three biological replicates were included for each strain. Comparative proteomic analyses of Synechocystis 6803 and JU547 were conducted 
following our previously published method ${ }^{47}$. In brief, cell pellets taken out of $-80^{\circ} \mathrm{C}$ were lysed by sonication with a program of 12 cycles of 10-sec-on-2-minoff on ice. The supernatants were collected via centrifugation and the protein concentrations were analyzed using Bradford assay (Thermo Scientific, Rockford, IL). Then, $75 \mu \mathrm{g}$ of total protein for each sample was denatured by incubating with $8 \mathrm{M}$ urea and $5 \mathrm{mM}$ dithiothreitol (DTT) at $37^{\circ} \mathrm{C}$ for an hour, followed by protein alkylation with $15 \mathrm{mM}$ iodoacetamide for $30 \mathrm{~min}$ in the dark at room temperature. Next, the protein solution was diluted fourfolds with the Tris buffer $(50 \mathrm{mM}$ Tris $\cdot \mathrm{HCl}, \mathrm{pH} 8.0$, and $10 \mathrm{mM} \mathrm{CaCl}_{2}$ ), and then digested with Trypsin Gold (Promega, Madison, WI) with an enzyme/protein ratio of 1:100 (w/w) for $18 \mathrm{~h}$ at $37^{\circ} \mathrm{C}$. After digestion, peptides were desalted by passing through a Sep-Pak C18 plus column (Waters Corporation, Milford, MA) and eluted with $1 \mathrm{~mL}$ of Solvent B ( $0.1 \%$ formic acid, $70 \%$ acetonitrile, and $30 \%$ water). The peptides were then dried completely in a SpeedVac and redissolved in $100 \mu \mathrm{L}$ of Solvent A $(0.1 \%$ formic acid, $5 \%$ acetonitrile, and $95 \%$ water). The entire peptides were loaded onto an in-house packed biphasic strong cation-exchange (SCX)/reverse-phase capillary column using a pressure cell. Online two-dimensional peptide separation was conducted using a liquid chromatography pump (Surveyor MS Pump Plus, Thermo Scientific, San Jose, CA) by pulsing with eleven increasing concentrations of ammonium acetate for SCX separation, followed by a 2-h reverse-phase gradient program from $100 \%$ Solvent A to $60 \%$ Solvent B. The peptides were continuously emitted and analyzed in a Thermo Scientific LTQ XL ion trap mass spectrometer (Thermo Scientific, San Jose, CA) operated under the data-dependent acquisition mode. The full mass spectra were collected using the Xcalibur data system (Thermo Scientific, San Jose, CA) in the range of $300-1700 \mathrm{~m} / \mathrm{z}$, followed by selecting the top five most abundant ions for the collision-induced dissociation tandem mass (MS/MS) events. To analyze the peptide information, a protein database was generated using the Synechocystis sp. proteins obtained from UniProt database and 37 common contaminant proteins. The tandem mass spectra were analyzed using the proteomics search algorithm ProLuCID (version 1.0 ${ }^{48}$, followed by peptide screening using DTASelect (version 2.0) ${ }^{49}$ with a false discovery rate of 0.05 . A minimum of two peptides were used to identify a protein. Comparison of protein levels was conducted using the pipeline software Patternlab for Proteomics (version 4.0.0.38) ${ }^{50}$ using the TFold test. Proteins that satisfy both fold change and $p$-value were used to indicate differential expression levels between the compared groups. The raw proteomics data have been deposited to the ProteomeXchange Consortium ${ }^{51}$ with the dataset identifier PXD025040.

Reporting summary. Further information on research design is available in the Nature Research Reporting Summary linked to this article.

\section{Data availability}

Data supporting the findings of this work are available within the paper and its Supplementary Information files. A reporting summary for this Article is available as a Supplementary Information file. The original proteomics dataset generated in this study has been deposited to the ProteomeXchange Consortium ${ }^{51}$ with the dataset identifier PXD025040. The DNA sequencing data confirming the intact or mutated efe-insertion region of the cyanobacterial genomes are included in Supplementary Data 2, and have been deposited to GenBank with accession numbers MZ465674, MZ465675, MZ465676, and MZ465677. Source data are provided with this paper.

Received: 1 February 2021; Accepted: 5 August 2021; Published online: 26 August 2021

\section{References}

1. Güthner, T., Mertschenk, B. \& Schulz, B. Guanidine and Derivatives. In Ullmann's Encyclopedia of Industrial Chemistry (ed.) 17, 175-189 (WileyVCH Verlag GmbH \& Co. KGaA, 2006).

2. Zhang, Z., Nyborg, M., Worsley, M., Worsley, K. M. \& Gower, D. A. Guanidine sulphate: slow release of mineral nitrogen during incubation in soil. Commun. Soil Sci. Plant Anal. 23, 431-439 (1992).

3. Putnam, D. F. Composition and Concentrative Properties of Human Urine. Report No. NASA-CR-1802, DAC-61125-F (NASA, 1971).

4. Natelson, S. \& Sherwin, J. E. Proposed mechanism for urea nitrogen reutilization: relationship between urea and proposed guanidine cycles. Clin. Chem. 25, 1343-1344 (1979).

5. Nelson, J. W., Atilho, R. M., Sherlock, M. E., Stockbridge, R. B. \& Breaker, R. $\mathrm{R}$. Metabolism of free guanidine in bacteria is regulated by a widespread riboswitch class. Mol. Cell 65, 220-230 (2017).

6. Lewis, C. A. Jr. \& Wolfenden, R. The nonenzymatic decomposition of guanidines and amidines. J. Am. Chem. Soc. 136, 130-136 (2014).

7. Mitchell, W. R. Biodegradation of guanidinium ion in aerobic soil samples. Bull. Environ. Contam Toxicol. 39, 974-981 (1987).
8. Sherlock, M. E., Malkowski, S. N. \& Breaker, R. R. Biochemical validation of a second guanidine riboswitch class in bacteria. Biochemistry 56, 352-358 (2017).

9. Sherlock, M. E. \& Breaker, R. R. Biochemical validation of a third guanidine riboswitch class in bacteria. Biochemistry 56, 359-363 (2017).

10. Lenkeit, F., Eckert, I., Hartig, J. S. \& Weinberg, Z. Discovery and characterization of a fourth class of guanidine riboswitches. Nucleic Acids Res. 48, 12889-12899 (2020).

11. Salvail, H., Balaji, A., Yu, D., Roth, A. \& Breaker, R. R. Biochemical validation of a fourth guanidine riboswitch class in bacteria. Biochemistry 59, 4654-4662 (2020).

12. Kermani, A. A., Macdonald, C. B., Gundepudi, R. \& Stockbridge, R. B. Guanidinium export is the primal function of SMR family transporters. Proc. Natl Acad. Sci. USA 115, 3060-3065 (2018).

13. Schneider, N. O. et al. Solving the conundrum: widespread proteins annotated for urea metabolism in bacteria are carboxyguanidine deiminases mediating nitrogen assimilation from guanidine. Biochemistry 59, 3258-3270 (2020).

14. Kaneko, T. et al. Sequence analysis of the genome of the unicellular cyanobacterium Synechocystis sp. strain PCC6803. II. Sequence determination of the entire genome and assignment of potential protein-coding regions. DNA Res. 3, 109-136 (1996).

15. Sekowska, A., Danchin, A. \& Risler, J. L. Phylogeny of related functions: the case of polyamine biosynthetic enzymes. Microbiology 146, 1815-1828 (2000). Pt 8 .

16. Cunin, R., Glansdorff, N., Pierard, A. \& Stalon, V. Biosynthesis and metabolism of arginine in bacteria. Microbiol. Rev. 50, 314-352 (1986).

17. Eckert, C. et al. Ethylene-forming enzyme and bioethylene production. Biotechnol. Biofuels 7, 33 (2014).

18. Guerrero, F., Carbonell, V., Cossu, M., Correddu, D. \& Jones, P. R. Ethylene synthesis and regulated expression of recombinant protein in Synechocystis sp. PCC 6803. PLoS ONE 7, e50470 (2012).

19. Ungerer, J. et al. Sustained photosynthetic conversion of $\mathrm{CO}_{2}$ to ethylene in recombinant cyanobacterium Synechocystis 6803. Energy Environ. Sci. 5, 8998-9006 (2012).

20. Zhu, T., Xie, X., Li, Z., Tan, X. \& Lu, X. Enhancing photosynthetic production of ethylene in genetically engineered Synechocystis sp. PCC 6803. Green. Chem. 17, 421-434 (2015).

21. Xiong, W. et al. The plasticity of cyanobacterial metabolism supports direct $\mathrm{CO}_{2}$ conversion to ethylene. Nat. Plants 1, 15053 (2015).

22. Wang, J. P. et al. Metabolic engineering for ethylene production by inserting the ethylene-forming enzyme gene (efe) at the 16S rDNA sites of Pseudomonas putida KT2440. Bioresour. Technol. 101, 6404-6409 (2010).

23. Sakai, M., Ogawa, T., Matsuoka, M. \& Fukuda, H. Photosynthetic conversion of carbon dioxide to ethylene by the recombinant cyanobacterium, Synechococcus sp. PCC 7942, which harbors a gene for the ethylene-forming enzyme of Pseudomonas syringae. J. Fermentation Bioeng. 84, 434-443 (1997)

24. Takahama, K., Matsuoka, M., Nagahama, K. \& Ogawa, T. Construction and analysis of a recombinant cyanobacterium expressing a chromosomally inserted gene for an ethylene-forming enzyme at the psbAI locus. J. Biosci. Bioeng. 95, 302-305 (2003).

25. Sengupta, A. et al. Photosynthetic co-production of succinate and ethylene in a fast-growing cyanobacterium, Synechococcus elongatus PCC 11801. Metabolites 10, 250 (2020).

26. Forchhammer, K. \& Schwarz, R. Nitrogen chlorosis in unicellular cyanobacteria-a developmental program for surviving nitrogen deprivation. Environ. Microbiol. 21, 1173-1184 (2019).

27. Wang, B. et al. Photosynthetic production of the nitrogen-rich compound guanidine. Green. Chem. 21, 2928-2937 (2019).

28. Satishchandran, C. \& Boyle, S. M. Purification and properties of agmatine ureohydrolyase, a putrescine biosynthetic enzyme in Escherichia coli. J. Bacteriol. 165, 843-848 (1986).

29. Veaudor, T., Cassier-Chauvat, C. \& Chauvat, F. Genomics of urea transport and catabolism in cyanobacteria: biotechnological implications. Front. Microbiol. 10, 2052 (2019).

30. Nagahama, K. et al. Purification and properties of an ethylene-forming enzyme from Pseudomonas syringae pv. phaseolicola PK2. J. Gen. Microbiol. 137, 2281-2286 (1991).

31. Ishihara, K. et al. Overexpression and in vitro reconstitution of the ethyleneforming enzyme from Pseudomonas syringae. J. Fermentation Bioeng. 79, 205-211 (1995).

32. Wang, B., Eckert, C., Maness, P. C. \& Yu, J. A genetic toolbox for modulating the expression of heterologous genes in the cyanobacterium Synechocystis sp. PCC 6803. ACS Synth. Biol. 7, 276-286 (2018).

33. Burnat, M., Li, B., Kim, S. H., Michael, A. J. \& Flores, E. Homospermidine biosynthesis in the cyanobacterium Anabaena requires a deoxyhypusine synthase homologue and is essential for normal diazotrophic growth. Mol. Microbiol. 109, 763-780 (2018). 
34. Burnat, M., Picossi, S., Valladares, A., Herrero, A. \& Flores, E. Catabolic pathway of arginine in Anabaena involves a novel bifunctional enzyme that produces proline from arginine. Mol. Microbiol. 111, 883-897 (2019).

35. Zhang, H. et al. The cyanobacterial ornithine-ammonia cycle involves an arginine dihydrolase. Nat. Chem. Biol. 14, 575-581 (2018).

36. Quintero, M. J., Muro-Pastor, A. M., Herrero, A. \& Flores, E. Arginine catabolism in the cyanobacterium Synechocystis sp. Strain PCC 6803 involves the urea cycle and arginase pathway. J. Bacteriol. 182, 1008-1015 (2000).

37. Kuchmina, E. et al. Ethylene production in Synechocystis sp. PCC 6803 promotes phototactic movement. Microbiology 163, 1937-1945 (2017).

38. Heyda, J. et al. Guanidinium can both cause and prevent the hydrophobic collapse of biomacromolecules. J. Am. Chem. Soc. 139, 863-870 (2017).

39. Zheng, W. et al. Probing the action of chemical denaturant on an intrinsically disordered protein by simulation and experiment. J. Am. Chem. Soc. 138, 11702-11713 (2016).

40. Yang, H. J. \& Tsou, C. L. Inactivation during denaturation of ribonuclease A by guanidinium chloride is accompanied by unfolding at the active site. Biochem J. 305, 379-384 (1995).

41. Lees, H. \& Quastel, J. H. Biochemistry of nitrification in soil; nitrification of various organic nitrogen compounds. Biochem J. 40, 824-828 (1946).

42. Carbonell, V., Vuorio, E., Aro, E. M. \& Kallio, P. Enhanced stable production of ethylene in photosynthetic cyanobacterium Synechococcus elongatus PCC 7942. World J. Microbiol Biotechnol. 35, 77 (2019).

43. Cheah, Y. E. et al. Systematic identification and elimination of flux bottlenecks in the aldehyde production pathway of Synechococcus elongatus PCC 7942. Metab. Eng. 60, 56-65 (2020).

44. Wang, B., Yu, J., Zhang, W. \& Meldrum, D. R. Premethylation of foreign DNA improves integrative transformation efficiency in Synechocystis sp. strain PCC 6803. Appl Environ. Microbiol. 81, 8500-8506 (2015).

45. Golden, S. S., Brusslan, J. \& Haselkorn, R. Genetic engineering of the cyanobacterial chromosome. Methods Enzymol. 153, 215-231 (1987).

46. Jazmin, L. J. et al. Isotopically nonstationary (13)C flux analysis of cyanobacterial isobutyraldehyde production. Metab. Eng. 42, 9-18 (2017).

47. Wang, X. et al. Enhanced limonene production in cyanobacteria reveals photosynthesis limitations. Proc. Natl Acad. Sci. USA 113, 14225-14230 (2016).

48. Xu, T. et al. ProLuCID: an improved SEQUEST-like algorithm with enhanced sensitivity and specificity. J. Proteom. 129, 16-24 (2015).

49. Tabb, D. L., McDonald, W. H. \& Yates, J. R. 3rd DTASelect and Contrast: tools for assembling and comparing protein identifications from shotgun proteomics. J. Proteome Res. 1, 21-26 (2002).

50. Carvalho, P. C., Fischer, J. S., Chen, E. I., Yates, J. R. 3rd \& Barbosa, V. C. PatternLab for proteomics: a tool for differential shotgun proteomics. BMC Bioinforma. 9, 316 (2008).

51. Vizcaino, J. A. et al. 2016 update of the PRIDE database and its related tools. Nucleic Acids Res. 44, 11033 (2016).

\section{Acknowledgements}

The authors would like to thank Dr. Chi Zhao for his assistance in analyzing ammonium. This work was authored in part by Alliance for Sustainable Energy, LLC, the manager and operator of the National Renewable Energy Laboratory for the U.S. Department of
Energy (DOE) under Contract No. DE-AC36-08GO28308. Funding was provided by DOE Office of Energy Efficiency and Renewable Energy BioEnergy Technologies Office (B.W. and J.Yu.). This study was supported in part by the DOE Genomic Science Program under award DE-SC0019404 (B.W., Y.X., C.H.J. and J.D.Y.), DE-SC0019388 (B.W. and J.D.Y), and DE-SC0018344 (B.W. and J.D.Y), and grants from the NIH/NIGMS (R37 GM067152 and R01 GM107434 to C.H.J.) and by DE-AR0000203 (X.W. and J.S.Yuan)

\section{Author contributions}

B.W. and J.Yu. conceived the work. B.W. designed and performed most of the experiments and drafted the manuscript. Y.X. constructed recombinant Synechococcus elongatus strains. X.W. and J.Yuan performed proteomic analysis. C.H.J and J.D.Y. performed discussion, critical review, and revision of the manuscript. All authors read and approved the manuscript.

\section{Competing interests}

B.W. and J.Yu were listed as inventors in a provisional patent application (Application No. 63126828), which is about the application of the guanidine-degrading enzyme for detoxifying guanidine and for enhanced bioproduction. The remaining authors declare no competing interests.

\section{Additional information}

Supplementary information The online version contains supplementary material available at https://doi.org/10.1038/s41467-021-25369-x.

Correspondence and requests for materials should be addressed to B.W. or J.Y.

Peer review information Nature Communications thanks Enrique Flores and other, anonymous, reviewers for their contributions to the peer review of this work.

Reprints and permission information is available at http://www.nature.com/reprints

Publisher's note Springer Nature remains neutral with regard to jurisdictional claims in published maps and institutional affiliations.

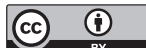

Open Access This article is licensed under a Creative Commons Attribution 4.0 International License, which permits use, sharing, adaptation, distribution and reproduction in any medium or format, as long as you give appropriate credit to the original author(s) and the source, provide a link to the Creative Commons license, and indicate if changes were made. The images or other third party material in this article are included in the article's Creative Commons license, unless indicated otherwise in a credit line to the material. If material is not included in the article's Creative Commons license and your intended use is not permitted by statutory regulation or exceeds the permitted use, you will need to obtain permission directly from the copyright holder. To view a copy of this license, visit http://creativecommons.org/ licenses/by/4.0/.

This is a U.S. Government work and not under copyright protection in the US; foreign copyright protection may apply 2021 